\title{
Water Splitting: From Electrode to Green Energy System
}

Cite as

Nano-Micro Lett.

(2020) 12:131

Received: 6 April 2020

Accepted: 21 May 2020

Published online: 17 June 2020

(C) The Author(s) 2020

\author{
Xiao $\mathrm{Li}^{1}$, Lili Zhao ${ }^{1}$, Jiayuan $\mathrm{Yu}^{1}$, Xiaoyan Liu ${ }^{1}$, Xiaoli Zhang ${ }^{3}$, Hong Liu ${ }^{1,2}{ }^{凶}$, \\ Weijia Zhou ${ }^{1}$ \\ Xiao Li, Lili Zhao and Jiayuan Yu contributed equally to this work. \\ \Hong Liu,hongliu@sdu.edu.cn; Weijia Zhou,ifc_zhouwj@ujn.edu.cn \\ 1 Collaborative Innovation Center of Technology and Equipment for Biological Diagnosis and Therapy \\ in Universities of Shandong, Institute for Advanced Interdisciplinary Research (iAIR), University of Jinan, \\ Jinan 250022, People's Republic of China \\ 2 State Key Laboratory of Crystal Materials, Shandong University, Jinan 250100, People's Republic of China \\ 3 School of Materials Science and Engineering, Zhengzhou University, Zhengzhou 450001, \\ People's Republic of China
}

\section{HIGHLIGHTS}

- Bifunctional electrode and electrolytic cell configuration for electrochemical water splitting are reviewed.

- The different green energy systems powered water splitting are summarized and discussed.

- An outlook of future research prospects for the development of green energy system powered water splitting in practical application process is proposed.

ABSTRACT Hydrogen $\left(\mathrm{H}_{2}\right)$ production is a latent feasibility of renewable clean energy. The industrial $\mathrm{H}_{2}$ production is obtained from reforming of natural gas, which consumes a large amount of nonrenewable energy and simultaneously produces greenhouse gas carbon dioxide. Electrochemical water splitting is a promising approach for the $\mathrm{H}_{2}$ production, which is sustainable and pollution-free. Therefore, developing efficient and economic technologies for electrochemical water splitting has been an important goal for researchers around the world. The utilization of green energy systems to reduce overall energy consumption is more important for $\mathrm{H}_{2}$ production. Harvesting and converting energy from the environment by different green energy systems for water splitting can efficiently decrease the external power consumption. A variety of green energy systems for efficient producing $\mathrm{H}_{2}$, such as two-electrode electrolysis of water, water splitting driven by photoelectrode devices, solar cells, thermoelectric devices, triboelectric nanogenerator, pyroelectric device or electrochemical water-gas shift device, have been

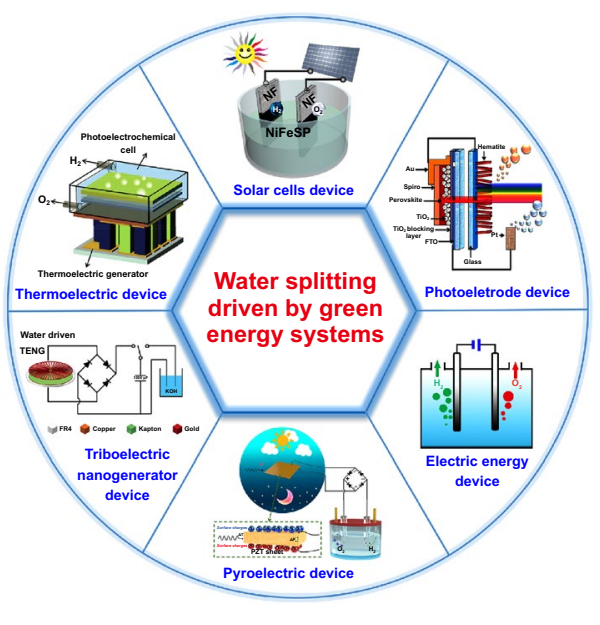
developed recently. In this review, some notable progress made in the different green energy cells for water splitting is discussed in detail. We hoped this review can guide people to pay more attention to the development of green energy system to generate pollution-free $\mathrm{H}_{2}$ energy, which will realize the whole process of $\mathrm{H}_{2}$ production with low cost, pollution-free and energy sustainability conversion.

KEYWORDS Water splitting; Electrode; Green energy system; Renewable energy; Hydrogen production 


\section{Introduction}

With the gradual intensity of global energy crisis, hydrogen $\left(\mathrm{H}_{2}\right)$ is one of the most sustainable and clean energies for replacing fossil fuel energy [1,2]. Reforming natural gas to produce $\mathrm{H}_{2}$ not only consumes a large amount of natural resources but also produces undesired carbon dioxide, which causes greenhouse effect [3-5]. Splitting water into $\mathrm{H}_{2}$ and oxygen $\left(\mathrm{O}_{2}\right)$ was from more than 200 years ago. It is very important to develop an environmental-friendly and low-cost technology for large-scale production of $\mathrm{H}_{2}$ [6]. As a mature energy conversion technology, electrolysis of water provides a simple, efficient and promising method for the hydrogen evolution reaction (HER) [7-10]. However, an external power supply to deliver oxidation or reduction reactions of $\mathrm{H}_{2} \mathrm{O}$ is necessary for electrolysis, leading to economically inefficient application of energy. Alternatively, harvesting, storing and converting energy from the environment (such as wind, thermal, sunlight, tidal and self-powdered energy) $[11,12]$ can be directly utilized for electrolysis with using a lower or no external power supply.

Sunlight is an inexhaustible renewable energy source that can meet humanity's needs. Effective utilization of solar energy can reduce the overall energy consumption of water splitting $[13,14]$. For example, constructing a photoelectrode to absorb sunlight can provide a photovoltage to effectively reduce the external energy supply for electrolysis of water $[15,16]$. In addition, solar cell is also an effective technology of solar energy conversion, which can directly absorb sunlight to transform output voltage instead of external electric energy, thus effectively realizing the minimum of external energy consumption. The utilization of heat energy from sunlight in nature for thermoelectric (TE) device can generate power to provide the voltage of water splitting [17]. There are also vast amount of wind and tidal energy in nature, which can be captured by triboelectric nanogenerator (TENG) to generate electricity, which can also effectively reduce the input of external energy. Therefore, it is of great significance to establish a suitable externally driven system of water splitting to reduce external consumption and improve $\mathrm{H}_{2}$ production capacity.

For the past few years, many researchers have developed a variety of green energy system for efficient producing $\mathrm{H}_{2}$, such as two-electrode electrolysis of water, water splitting driven by a photoelectrode device, solar cells, TE device, TENG and other devices including pyroelectric and water-gas shift (WGS) reaction and so on (Fig. 1). These green energy systems can efficient drive water splitting for $\mathrm{H}_{2}$ production. Some notable matters and challenge in the different green energy system for water splitting are discussed in detail in this review.

\section{Two-Electrode Electrolysis of Water}

Electrochemical water splitting is a prospective method to produce environmentally friendly hydrogen fuel [18]. Electrochemical water splitting requires a voltage of $1.23 \mathrm{~V}$ in theory; however, over $1.8 \mathrm{~V}$ is needed in practice to overcome the activation barrier of the reaction [19]. The large overpotential is from the slow four-electron transfer kinetics of the anodic oxidation reaction and the easy two-electron transfer kinetics of the cathode reduction reaction [20,21]. In addition, it is difficult to establish a water splitting system of different cathode and anode because different catalysts are active and stable in different $\mathrm{pH}$ ranges. Moreover, the use of different catalysts in the same system often needs different equipment and methods, which increases the complicacy and cost of the system. And also, the wettability of the electrocatalyst with electrolyte and the rapid desorption of bubbles generated on the electrodes are very important in the process

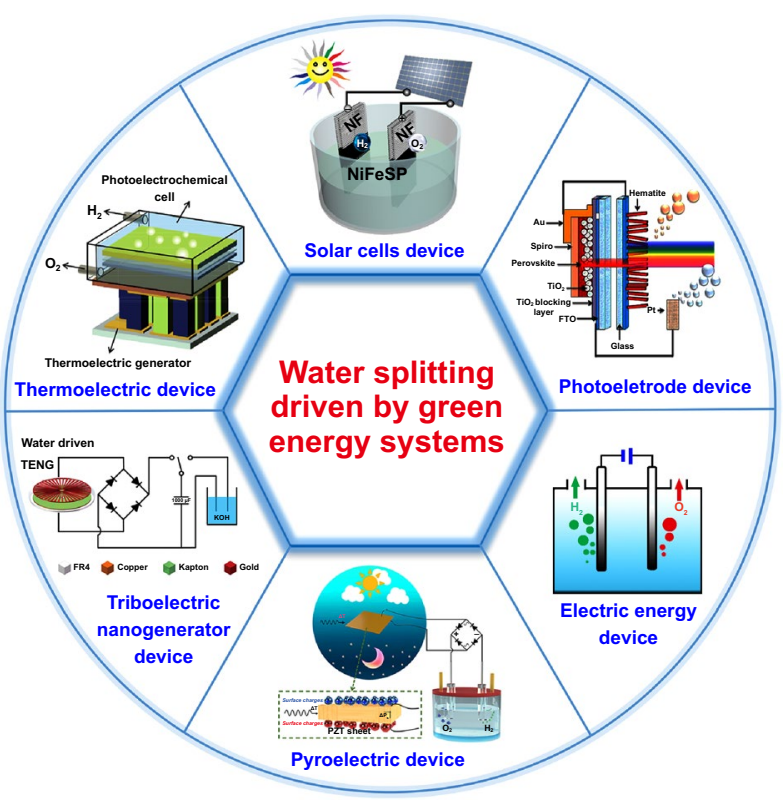

Fig. 1 Water splitting driven by different green energy systems 
of water splitting [22-24]. If the generated gas bubbles are difficult to break away from the surface of electrode, the active site of electrocatalyst will be covered as well as the electrolyte will be difficult to diffuse to access the interface of catalyst/electrolyte [25]. Therefore, the hydrophilicity and aerophobicity of the electrode is very significant to promote the efficiency and stability of the water splitting process [26, 27]. Hence, the development of a high active, stable and low-cost bifunctional electrocatalyst for water splitting is imperative [28].

\subsection{Electrocatalysts for Overall Water Splitting}

For overall water splitting, an ideal bifunctional electrocatalyst should be a low-cost, highly active and economical preparation method, which can provide long-term stability for both HER and oxygen evolution reaction (OER) in the electrolyte [29]. The employment of suitable catalyst will be critical to develop electrolysis of water. Hence, it is an urgent desire for researchers to develop many different kinds of bifunctional electrocatalysts with different performance to promote the development of $\mathrm{H}_{2}$ fuels [30].

Transition metal oxide [31,32], transition metal sulfides [33-39] and selenides [40-43], transition metal phosphides [44-49], transition metal nitrides [50-52] become potential candidates as non-noble metal electrocatalysts for electrolysis of water. The $\mathrm{Ni}_{3} \mathrm{~S}_{2} / \mathrm{MnS}-\mathrm{O}$ nanosheets on $\mathrm{Ni}$ foam $\left(\mathrm{NF} / \mathrm{T}\left(\mathrm{Ni}_{3} \mathrm{~S}_{2} / \mathrm{MnS}-\mathrm{O}\right)\right)$ were employed as anode and cathode for overall water splitting (Fig. 2a), which was required a voltage of $1.54 \mathrm{~V}$ at a current density of $10 \mathrm{~mA} \mathrm{~cm}^{-2}$ [33]. Dai and Liu et al. prepared NiCo-nitrides $/ \mathrm{NiCo}_{2} \mathrm{O}_{4} / \mathrm{GF}$ as both anode and cathode in two-electrode system; the whole voltage for electrochemical water splitting was $1.68 \mathrm{~V}$ to achieve $20 \mathrm{~mA} \mathrm{~cm}^{-2}$ in $1.0 \mathrm{M} \mathrm{KOH} \mathrm{(Fig.} \mathrm{2b)} \mathrm{[53].} \mathrm{He} \mathrm{and}$ Sun et al. synthesized a bifunctional catalyst for electrolysis of water based on three-dimensional (3D) self-supported Fedoped $\mathrm{Ni}_{2} \mathrm{P}$ nanosheets on NF. An two-electrode electrolyzer composed of the $\left(\mathrm{Ni}_{0.33} \mathrm{Fe}_{0.67}\right)_{2} \mathrm{P} \|\left(\mathrm{Ni}_{0.33} \mathrm{Fe}_{0.67}\right)_{2} \mathrm{P}$ electrodes required a low cell voltage of $1.49 \mathrm{~V}$ to achieve $10 \mathrm{~mA} \mathrm{~cm}^{-2}$ in $1.0 \mathrm{M} \mathrm{KOH}$ [45]. Wang et al. reported that the nanostructured porous $\mathrm{Ni}_{3} \mathrm{FeN}$ nanosheet was obtained by annealing process the $\mathrm{Ni}_{3} \mathrm{Fe} \mathrm{LDHs}$ precursor in $\mathrm{NH}_{3}$ atmosphere. The porous $\mathrm{Ni}_{3} \mathrm{FeN}$ used as both anode and cathode in twoelectrode system for overall water splitting in $1.0 \mathrm{M} \mathrm{KOH}$ required a voltage of $1.495 \mathrm{~V}$ at $10 \mathrm{~mA} \mathrm{~cm}^{-2}$, which could be driven by a battery with rated voltage of $1.5 \mathrm{~V}$ [50]. Metalfree electrocatalysts also show high activity, good stability and low cost to replace metal-based electrocatalysts for longterm water splitting $[54,55]$. Yu, Chen, Dai et al. reported a novel metal-free bifunctional electrocatalyst with the ultrathin exfoliated black phosphorus (EBP) nanosheets on N-doped graphene (EBP@NG). EBP@NG possessed excellent performance of HER and OER in $1.0 \mathrm{M} \mathrm{KOH}$. The voltage of an optimized two-electrode cell with EBP@NG used as anode and cathode was $1.54 \mathrm{~V}$ to achieve $10 \mathrm{~mA} \mathrm{~cm}{ }^{-2}$ [54]. The voltage of most reported bifunctional non-noble metal electrocatalysts is lower than that of benchmarking $\mathrm{IrO}_{2} \| \mathrm{Pt}$ electrodes $\left(1.57 \mathrm{~V}\right.$ at $\left.10 \mathrm{~mA} \mathrm{~cm}{ }^{-2}\right)$ and standard coupled $\mathrm{Ni}$ and stainless steel $\left(1.73 \mathrm{~V}\right.$ at $\left.10 \mathrm{~mA} \mathrm{~cm}^{-2}\right)$ in the industrial application [56]. A detailed comparison of the HER and OER activities of recently reported electrocatalysts for overall water splitting are listed in Table 1.

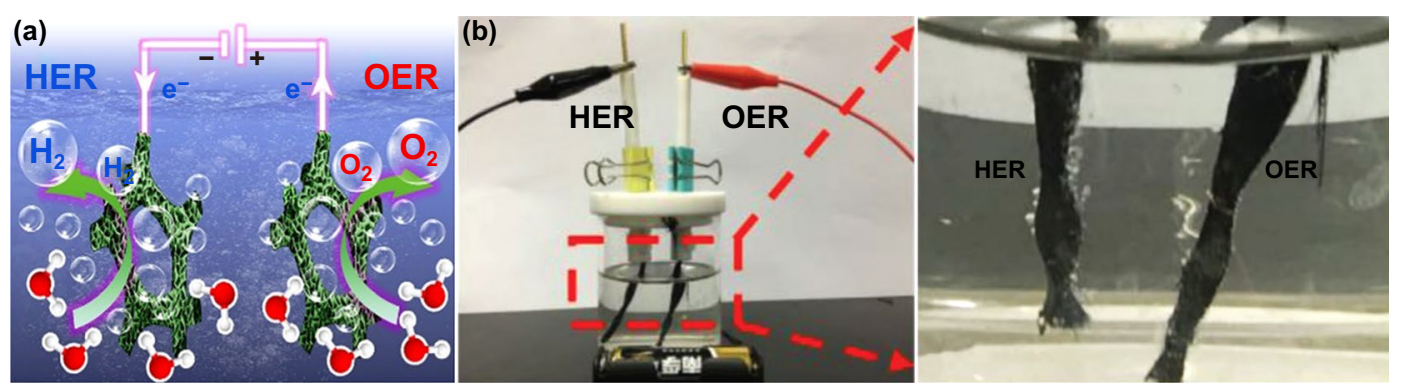

Fig. 2 a Schematic diagram of two-electrode configuration for overall water splitting with NF/T(Ni $\left.\mathrm{S}_{2} / \mathrm{MnS}-\mathrm{O}\right)$ as anode and cathode. Reproduced with permission from Ref. [33]. Copyright 2019 Elsevier Inc., b photographs showing the NiCo-nitrides/NiCo $\mathrm{O}_{4} / \mathrm{GF} / \mathrm{NiCo}-\mathrm{nitrides} /$ $\mathrm{NiCo}_{2} \mathrm{O}_{4} / \mathrm{GF}$ couple electrolyzer. Reproduced with permission from Ref. [53]. Copyright 2019 John Wiley and Sons 
Table 1 Summary of the HER and OER activities of recently reported electrocatalysts for overall water splitting

\begin{tabular}{|c|c|c|c|c|c|c|c|}
\hline Catalysis & Electrolytes & $\begin{array}{l}\eta \text { for HER } \\
\text { at } j(\mathrm{mV} @ \\
\left.\mathrm{mA} \mathrm{cm}{ }^{-2}\right)\end{array}$ & $\begin{array}{l}\eta \text { for OER } \\
\text { at } j(\mathrm{mV} @ \\
\left.\mathrm{mA} \mathrm{cm}{ }^{-2}\right)\end{array}$ & $\begin{array}{l}\text { Tafel slope } \\
\text { for HER (mV } \\
\left.\mathrm{dec}^{-1}\right)\end{array}$ & $\begin{array}{l}\text { Tafel slope } \\
\text { for OER (mV } \\
\left.\mathrm{dec}^{-1}\right)\end{array}$ & $\begin{array}{l}\text { Overall volt- } \\
\text { age at } j(\mathrm{~V} @ \\
\mathrm{mA} \mathrm{cm}\end{array}$ & References \\
\hline $\mathrm{Co}_{3} \mathrm{O}_{4} @ \mathrm{C} @ \mathrm{NF}$ & $1.0 \mathrm{M} \mathrm{KOH}$ & 42@10 & $96 @ 10$ & 56 & 89 & $1.40 @ 10$ & Ha et al. [31] \\
\hline $\mathrm{NF} / \mathrm{H}-\mathrm{CoMoO}_{4}$ & $1.0 \mathrm{M} \mathrm{KOH}$ & 295@10 & - & 91 & - & 1.56@10 & Chi et al. [32] \\
\hline $\mathrm{NF} / \mathrm{T}\left(\mathrm{Ni}_{3} \mathrm{~S}_{2} / \mathrm{MnS}-\mathrm{O}\right)$ & $1.0 \mathrm{M} \mathrm{KOH}$ & 116@10 & 228@10 & 41 & 46 & 1.54@10 & Zhang et al. [33] \\
\hline $\mathrm{N}-\mathrm{CoS}_{2} / \mathrm{NF}$ & $1.0 \mathrm{M} \mathrm{KOH}$ & 28@10 & 200@20 & 42.6 & 55 & 1.50@10 & Yao et al. [34] \\
\hline $\mathrm{MoS}_{2} / \mathrm{NiS}$ & $1.0 \mathrm{M} \mathrm{KOH}$ & 244@10 & 370@11 & 97 & 108 & 1.64@10 & Qin et al. [35] \\
\hline $\begin{array}{l}\mathrm{MoS}_{2}-\mathrm{Ni}_{3} \mathrm{~S}_{2} \mathrm{HNRs} / \\
\mathrm{NF}\end{array}$ & $1.0 \mathrm{M} \mathrm{KOH}$ & 98@10 & 314@10 & 61 & 57 & $1.50 @ 10$ & Yang et al. [36] \\
\hline $\mathrm{Ni}_{3} \mathrm{~S}_{2} / \mathrm{NF}$ & $1.0 \mathrm{M} \mathrm{KOH}$ & 189@10 & 296@10 & 89.3 & 65.1 & 1.55@10 & Li et al. [37] \\
\hline $\mathrm{MoS}_{2} / \mathrm{NiS}_{2}$ & $1.0 \mathrm{M} \mathrm{KOH}$ & 62@10 & 278@10 & 50.1 & 91.7 & 1.59@10 & Lin et al. [38] \\
\hline $\begin{array}{l}\mathrm{Ni}_{3} \mathrm{Se}_{4} @ \mathrm{NiFe} \mathrm{LDH} / \\
\mathrm{CFC}\end{array}$ & $1.0 \mathrm{M} \mathrm{KOH}$ & 85@10 & 223@10 & 98.6 & 55.5 & 1.54@10 & Zhang et al. [40] \\
\hline $\begin{array}{l}\text { CoSe@NiFe LDH/ } \\
\text { NF }\end{array}$ & $1.0 \mathrm{M} \mathrm{KOH}$ & 98@10 & $201 @ 10$ & 89 & 39 & 1.53@10 & Sun et al. [41] \\
\hline $\mathrm{Co}-\mathrm{Ni}-\mathrm{Se} / \mathrm{C} / \mathrm{NF}$ & $1.0 \mathrm{M} \mathrm{KOH}$ & 90@10 & 275@30 & 81 & 63 & 1.6@10 & Ming et al. [42] \\
\hline $\mathrm{MoSe}_{2} / \mathrm{MXene}$ & $1.0 \mathrm{M} \mathrm{KOH}$ & 95@10 & 340@10 & 91 & 90 & 1.64@10 & Li et al. [43] \\
\hline $\mathrm{CoP}_{2} / \mathrm{RGO}$ & $1.0 \mathrm{M} \mathrm{KOH}$ & 88@10 & 300@10 & 50 & 96 & 1.56@10 & Wang et al. [44] \\
\hline$\left(\mathrm{Ni}_{0.33} \mathrm{Fe}_{0.67}\right)_{2} \mathrm{P}$ & $1.0 \mathrm{M} \mathrm{KOH}$ & 214@50 & 230@50 & - & 55.9 & 1.49@10 & Li et al. [45] \\
\hline $\mathrm{NF} @ \mathrm{Fe}_{2}-\mathrm{Ni}_{2} \mathrm{P} / \mathrm{C}$ & $1.0 \mathrm{M} \mathrm{KOH}$ & 39@10 & 205@10 & 30 & 52 & $1.57 @ 100$ & Sun et al. [46] \\
\hline NiCoP@NC NA/NF & $1.0 \mathrm{M} \mathrm{KOH}$ & 37@10 & $305 @ 50$ & 53.9 & 70.5 & 1.56@20 & Cao et al [47] \\
\hline CoFeP TPAs/Ni & $1.0 \mathrm{M} \mathrm{KOH}$ & 43@10 & 198@10 & 65.3 & 42 & 1.47@10 & Zhang et al. [48] \\
\hline Mo-NiCoP & $1.0 \mathrm{M} \mathrm{KOH}$ & 76@10 & $269 @ 10$ & 60 & 76.7 & $1.61 @ 10$ & Lin et al. [49] \\
\hline $\mathrm{Ni}_{3} \mathrm{FeN}$ & $1.0 \mathrm{M} \mathrm{KOH}$ & 45@10 & 223@10 & 75 & 40 & 1.495@10 & Wang et al. [50] \\
\hline $\mathrm{Ni}_{3} \mathrm{~N}-\mathrm{NiMoN}$ & $1.0 \mathrm{M} \mathrm{KOH}$ & 31@10 & 277@10 & 64 & 118 & 1.54@10 & Wu et al. [51] \\
\hline $\mathrm{CoAl}-\mathrm{Fe}_{2} \mathrm{~N} / \mathrm{Fe}_{3} \mathrm{~N}$ & $1.0 \mathrm{M} \mathrm{KOH}$ & 145@10 & 307@10 & 54 & 69 & $1.67 @ 10$ & Hu et al. [52] \\
\hline $\begin{array}{l}\text { NiCo-nitrides/ } \\
\mathrm{NiCo}_{2} \mathrm{O}_{4}\end{array}$ & $1.0 \mathrm{M} \mathrm{KOH}$ & $71 @ 10$ & 183@10 & 41 & 54 & 1.68@20 & Liu et al. [53] \\
\hline EBP@NG & $1.0 \mathrm{M} \mathrm{KOH}$ & 125@10 & 265@10 & 76 & 89 & $1.54 @ 10$ & Yuan et al. [54] \\
\hline
\end{tabular}

\subsection{Electrolytic Cell}

Conventional water electrolysis usually utilizes transition metal catalysts and diaphragms in alkaline electrolytes (alkaline water electrolysis, AWE) or noble metal catalysts and a proton exchange membrane in acidic media (PEM water electrolysis) [57, 58].

\subsubsection{Alkaline Water Electrolysis}

Since Troostwijk and Diemann first found the phenomenon of electrolysis of water in 1789, alkaline water electrolysis has been an established technique for $\mathrm{H}_{2}$ production. Therefore, alkaline electrocatalysis is the most widely used electrolysis technology on a business level in the world
[59-64]. In the AWE, the electrolyte is made up of a caustic potassium solution with a concentration of $20-30 \% \mathrm{KOH}$ [65-67]. The configurations of alkaline electrolyzer contain the conventional alkaline electrolyzer, the "zero-gap" alkaline electrolyzer and the membraneless or decoupled alkaline electrolyzer.

In conventional alkaline electrolyzer, the anode and cathode immersed in the electrolyte are located on either side of the flat current collector to facilitate a serial connection between cells [68]. $\mathrm{H}_{2}$ and $\mathrm{O}_{2}$ bubbles are formed in two electrolyte chambers; meanwhile, a membrane avoids the mixture of them (Fig. 3a). This method is easy to scale up to the massive volume production of $\mathrm{H}_{2}$. However, the resulting bubbles decrease the effective area of the electrodes and improve the resistance of the electrolytes, leading to low current densities. Another issue of AWE of Ni-based 

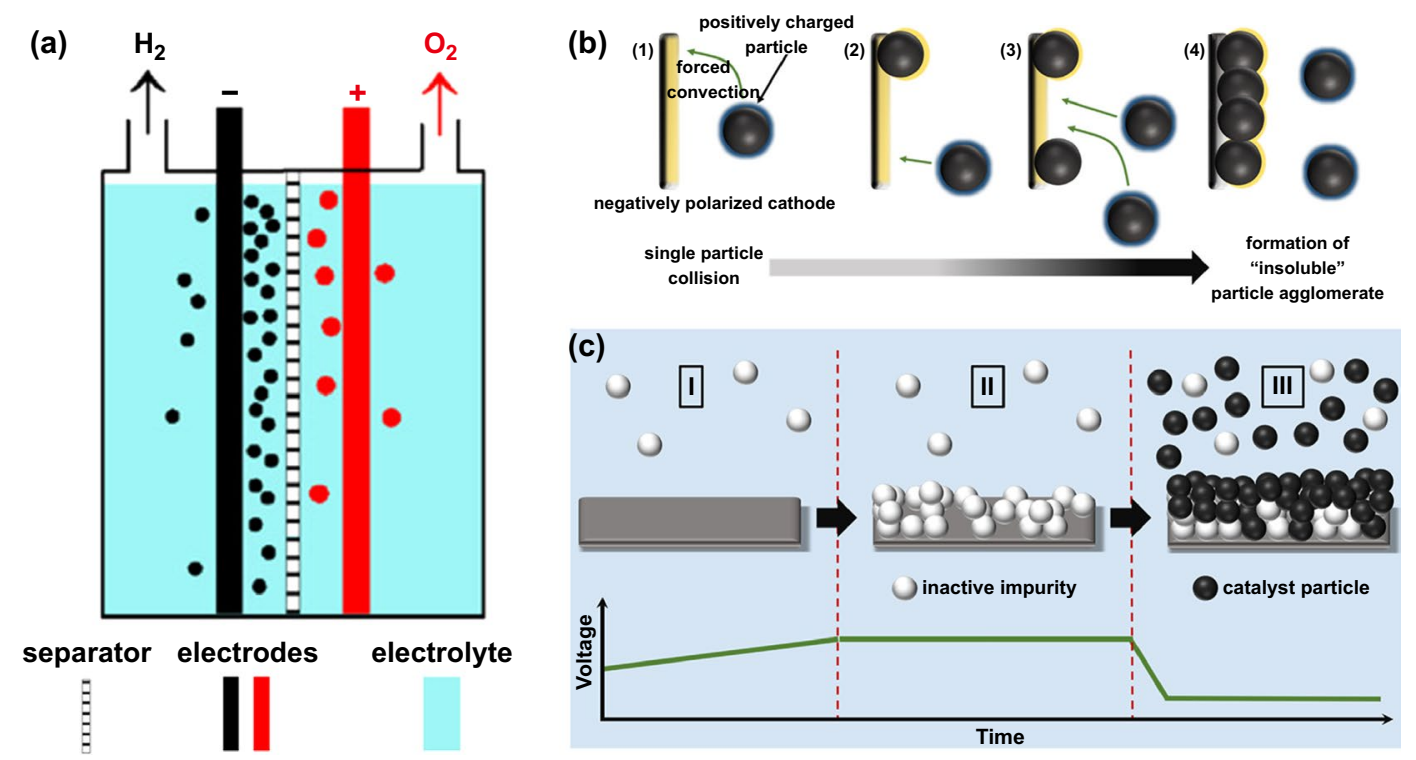

Fig. 3 a Schematic diagram of conventional alkaline electrolyzer. Reproduced with permission from Ref. [68]. Copyright 2012 Elsevier Inc., b schematic diagram of the formation of the catalyst film, $\mathbf{c}$ schematic diagram of cathode deactivation caused by the deposition of trace metal impurities and the change of the overall voltage in the electrolytic cell. Reproduced with permission from Ref. [69]. Copyright 2018 Elsevier Inc

electrodes is the sustaining attenuation of the activity for HER and OER. The deposition of metal cations mainly from electrolyte impurities can generate a surface coating with low catalytic activity, leading to reducing the activity for HER. Therefore, Schuhmann and Ventosa et al. creatively brought forward a method based on in situ self-assembly of catalyst particles in the electrolytic process to obtain exceptionally stable catalytic films with the capability of self-healing (Fig. 3b, c). They showed that the passivation of cathode by zinc impurities from the electrolyte could be surmounted by immobilizing catalyst with self-assembly and self-healing films. In the electrolytic process, zinc impurities deposited on the cathode electrode in the form of a dendritic film increased the HER overpotential, but the continued selfassembling and self-healing of the catalyst films following obscured the zinc dendrites that restored the favorable overpotential of the HER [69].

In the "zero-gap" configuration, a thin cellulose felt occupied the intra-electrode space can absorb the electrolyte, which is confined and clamped between two hydrophilic separators that are tightly pressed on the anode and cathode. The anode and cathode ought to be polyporous to permeate the liquid electrolyte. Therefore, the bubbles from the inner space of the electrode can be efficiently excluded [68]. For instance, Dunnill et al. reported that employing a zero-gap cell configuration could reduce $30 \%$ in ohmic resistance in comparison with the traditional a 2-mm gap in alkaline electrolyte (Fig. 4a, b). At all current densities, especially over $500 \mathrm{~mA} \mathrm{~cm}^{-2}$, the performance of zero-gap configuration cell was better than the standard cell. In addition, the foam electrodes with high surface area allowed for a low ohmic resistance compared to the coarse mesh electrodes. Therefore, the zero-gap configuration will permit low cost and high-efficiency alkaline electrolysis [70]. The anode and cathode also can be fabricated on the separators to further decrease the distance of the gap [71]. For instance, Tour et al. used the laser-induced graphene (LIG) to form HER and OER catalysts on each side of a polyimide (PI) film to assemble high-efficiency electrodes for electrolysis of water. In this alkaline electrolyzer, LIG was patterned on each side of a PI film and subsequently assembled LIG-Co-P and LIG-NiFe on opposite sides by electrochemical deposition (Fig. 4c, d). The hydroxide ions could migrate through a small pinhole at the end of the film that may be covered by ion exchange membranes for large-scale applications. As expected, the device of LIG-Co-P and LIG-NiFe for water splitting required $1.66 \mathrm{~V}$ to achieve a current density of $10 \mathrm{~mA} \mathrm{~cm}^{-2}$ in $1.0 \mathrm{M} \mathrm{KOH} \mathrm{[72].}$

In alkaline water electrolysis, the conductivity of liquid electrolyte is much higher than that of the ion exchange 

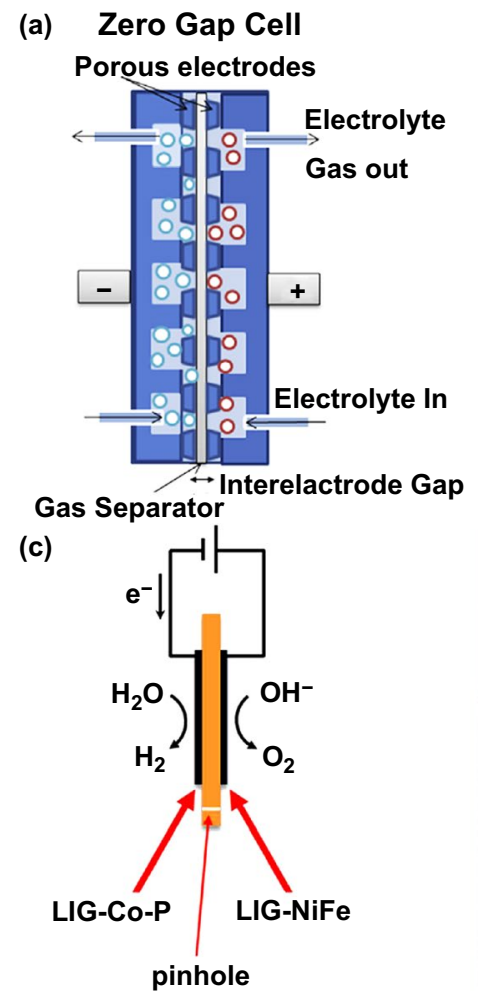
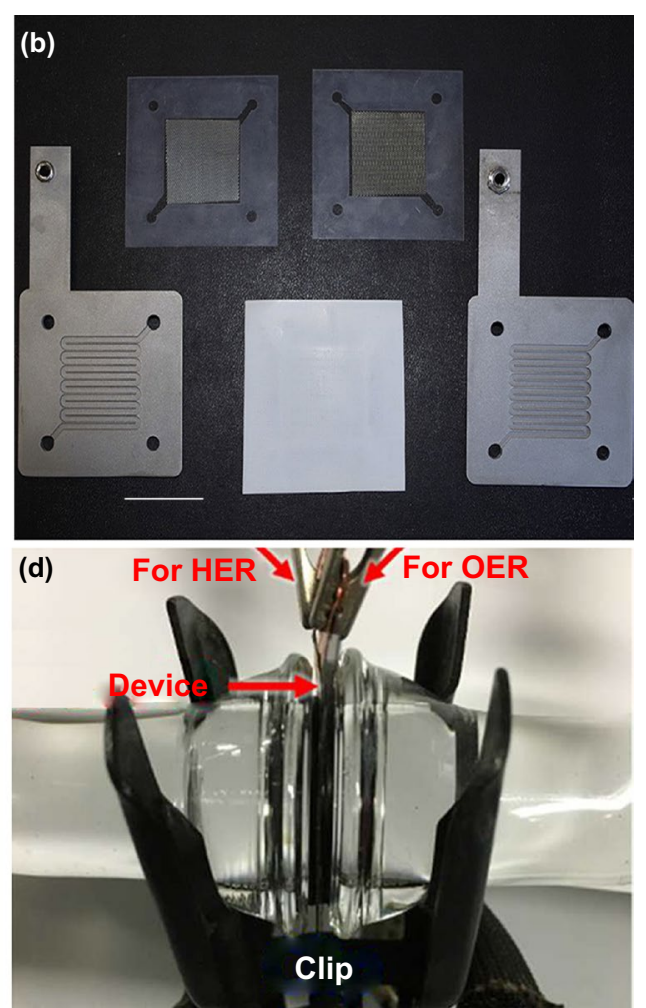

Fig. 4 a Schematic diagram for reducing the gap between electrodes by using a zero-gap cell, b components for the zero-gap cell, including the machined flow field plates, silicone gaskets, mesh electrodes and Zirfon gas separator. Reproduced with permission from Ref. [70]. Copyright 2017 Elsevier Inc., c schematic diagram and d a photograph of an integrated LIG electrolyzer. Reproduced with permission from Ref. [72]. Copyright 2017 American Chemical Society

membrane leading to significant ohmic losses [73, 74]. Therefore, Gillespie and Kriek constructed a membraneless DEFT alkaline electrolyzer for the gainful production of $\mathrm{H}_{2}$. The electrolyzer could overcome the limitation of current density threshold in the existing technology and was an ideal choice for $\mathrm{H}_{2}$ generation (Fig. 5a). The scale-up of the technology represented a difference from the design of original tested stack, which encapsulated many slender electrodes in a pressure filter assembly (Fig. 5b, c). The operation parameters of the pilot plant were limited to low flow rate, and the electrode gap was $2.5 \mathrm{~mm}$. The performance of the pilot plant is consistent with the previous acquired results. The geometric area of mesh electrodes used for the performance test of plant was $344.32 \mathrm{~cm}^{2}$. Under the conditions of $0.04 \mathrm{~m} \mathrm{~s}^{-1}, 30 \% \mathrm{KOH}, 2 \mathrm{~V}$ direct current (VDC) and $80{ }^{\circ} \mathrm{C}$, the best performance of the $\mathrm{NiO}$ anode and $\mathrm{Ni}$ cathode combination reached to $508 \mathrm{~mA} \mathrm{~cm}^{-2}$. Unfortunately, due to the nature of the gas-liquid separation system, the gas mass was insufficient in comparison with previous results [75].
To further promote the purities of the produced gas in the DEFT electrolyzer, Gillespie and Kriek developed an extensible and simple mono-circular filter press (MCFP) reactor for the DEFT alkaline electrolysis (Fig. 5d). Under the condition of the flow rate $\left(0.075 \mathrm{~m} \mathrm{~s}^{-1}\right)$ and electrode gap $(2.5 \mathrm{~mm})$, the utilized gas/liquid separation methodology improves the gas purities of $\mathrm{H}_{2}$ to $99.81 \mathrm{vol} \%$ and $\mathrm{O}_{2}$ to $99.50 \mathrm{vol} \%$. Each round mesh electrode pair of $30 \mathrm{~mm}$ has independent pressurized chamber and indirect injection of the electrolyte. By incorporating a gas purge, the high gas purity could be kept for a long running time. Using a $\mathrm{Ni} / \mathrm{Ni}$ catalyst, the current density was $1.14 \mathrm{~A} \mathrm{~cm}^{-2}$ (2.5 VDC) at a flow rate of $0.075 \mathrm{~m} \mathrm{~s}^{-1}, 60^{\circ} \mathrm{C}$ and 2.5 -mm electrode gap. Under the same condition except the utilization of a double-layer mesh electrode, a current density reached to $1.91 \mathrm{~A} \mathrm{~cm}^{-2}$ at $2.5 \mathrm{VDC}$ was realized, confirming that the multilayer microporous electrodes for the DEFT principle were available [76]. 


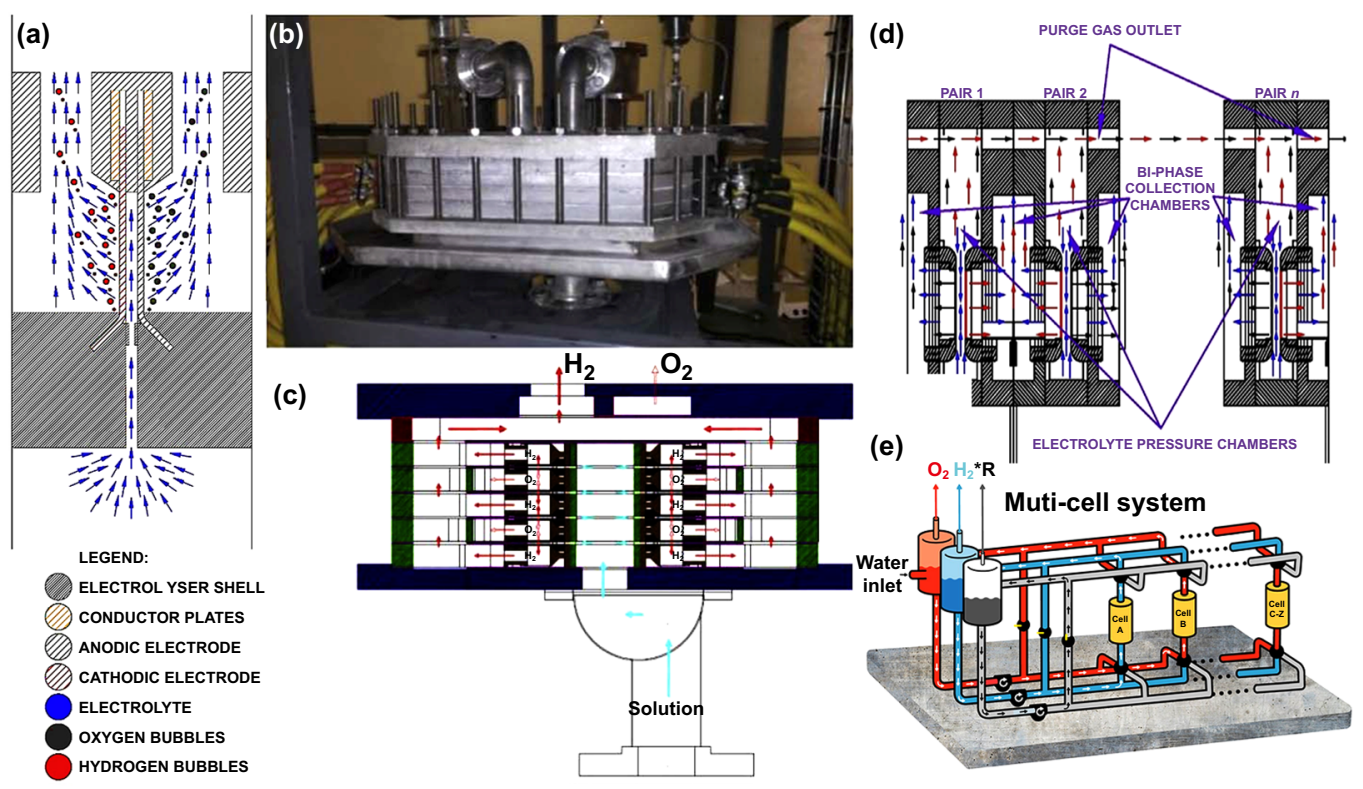

Fig. 5 a Schematic diagram of filtration mesh electrode encapsulated in a single injection assembly, $\mathbf{b}$ a photograph of the horizontal filter press DEFT electrolyzer stack, and $\mathbf{c}$ a diagram of a cross section of the electrolyzer stack assembly. Reproduced with permission from Ref. [75]. Copyright 2017 Elsevier Inc., d cross section of the DEFT electrolyzer stack in a MCFP configuration. Reproduced with permission from Ref. [76]. Copyright 2018 Elsevier Inc., e schematic diagram of the multicell system by the E-TAC process. Reproduced with permission from Ref. [83]. Copyright 2019 Springer Nature

Utilizing decoupled the two half-reactions of water splitting by redox mediators can completely avoid the mixture of produced $\mathrm{H}_{2}$ and $\mathrm{O}_{2}$, which is promising for large-scale practical application [77-82]. Grader et al. proposed a two-step electrochemical-thermally activated chemical (E-TAC) cycle for overall water splitting. $\mathrm{H}_{2}$ was produced by a HER at the cathode. The traditional OER was replaced by two steps. In the first step, the $\mathrm{Ni}(\mathrm{OH})_{2}$ anode was oxidized to $\mathrm{NiOOH}$ by four one-electron oxidation reactions. In the second step, the oxidized $\mathrm{NiOOH}$ could be spontaneously reduced to $\mathrm{Ni}(\mathrm{OH})_{2}$ in an exergonic chemical reaction to simultaneously achieve $\mathrm{O}_{2}$ production and anode regeneration. As shown in Fig. 5e, they also assumed a multicell system with fixed anodes and cathodes in each cell for practical application to produce pure $\mathrm{H}_{2}$ and $\mathrm{O}_{2}$ gas. A low-temperature electrolyte flew through cell $\mathrm{A}$, driving the produced $\mathrm{H}_{2}$ to the $\mathrm{H}_{2}$ separator. Meanwhile, a high-temperature electrolyte flew through cell $\mathrm{B}$ to regenerate the anode, driving the generated $\mathrm{O}_{2}$ to the $\mathrm{O}_{2}$ separator. In this multicell system, only hot and cold electrolyte moved in the operation process [83].

\subsubsection{PEM Water Electrolysis}

In 1960s, General Electric firstly proposed a concept of solid polymer electrolyte (SPE) concept for water electrolyzer, which predicted to conquer the disadvantages of alkaline electrolyzers. Grubb idealized the above concept by using solid sulfonated polystyrene membranes as the electrolytes, also known as PEM water electrolysis, rarely called SPE water electrolysis $[84,85]$. The polymer electrolyte membrane could provide higher proton conductivity, lower gas exchange, the compact design of system and operate under high pressure [86-90]. The advantages of solid polymer electrolyte were lower membrane thickness ( 20-300 $\mu \mathrm{m}$ thick).

First of all, the catalyst layer was coated on a glossy polytetrafluoroethylene (PTFE) sheet; then, the coating consisted of catalyst and Nafion ionomer on the surface of a Nafion 117 membrane was flat when the PTFE sheet was removed after being pressed against the membrane. The edge between the catalyst coating and membrane was 


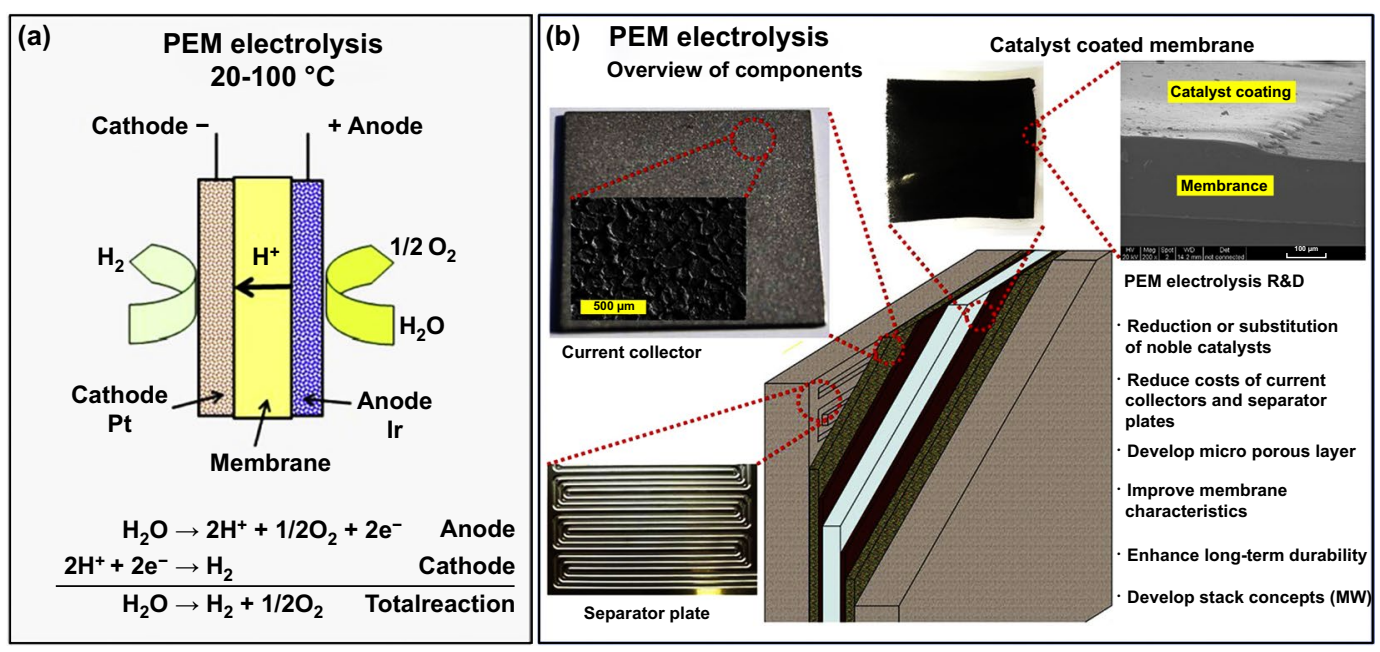

Fig. 6 a Schematic diagram of the working principle and b composition of a PEM water electrolysis. Reproduced with permission from Ref. [65]. Copyright 2013 Elsevier Inc

obvious on the surface of membrane. The thickness of the coating could change by adjusting the amount of catalyst ink [91]. In commercial PEM water electrolyzer, a layer consisted of $\mathrm{Pt} / \mathrm{C}$ and Nafion ionomer, similarly a layer of made up of $\mathrm{IrO}_{2}$ or $\mathrm{RuO}_{2}$ catalyst and Nafion ionomer, was coated on the opposite side of a Nafion 117 membrane, respectively (Fig. 6a).

The anode side of the PEM water electrolyzer was filled with water. Water successively passed through the separator plates and current collectors. When water got to the surface of catalyst layer, the molecules of water were broken up into protons, electrons and diatomic oxygen. Subsequently, the generated protons left the anode through the ionomer and the membrane, passing through the side of the cathode, where they coupled with electrons to form $\mathrm{H}_{2}$ after they arrived the catalytic layer. Then the $\mathrm{H}_{2}$ must flow through the cathode collector and the barrier, away from the cell. At the same time, the electrons left the cathode catalytic layer via the current collector, the separator plates, then departured to the side of the cathode. $\mathrm{O}_{2}$ must flow back via the catalyst layer and current collector to the separator plates then go out of the cell (Fig. 6b) [65].

The PEM electrolyzers could work at high current densities of over $2 \mathrm{~A} \mathrm{~cm}^{-2}$, reducing the operating cost and the potential total cost of water electrolysis. The ohmic losses confined the maximum value of current densities. The thin membrane capable of providing good proton conductivity and high current densities could be achieved. The low gas crossover rate of the polymer electrolyte membrane allowed for the PEM electrolyzer to operate at a wide range of power input.

The phenomenon of cross-permeation enlarged along with high operational pressure in PEM electrolysis [92]. High pressures (over 100 bar) required thicker membranes to reduce the mixture of $\mathrm{H}_{2}$ and $\mathrm{O}_{2}$, which kept the marginal concentrations below the safety threshold $\left(4 \mathrm{vol} \% \mathrm{H}_{2}\right.$ in $\mathrm{O}_{2}$ ) [92]. The corrosive acidic regime in the PEM electrolysis required distinct materials, which needed the resistance to severe corrosive low $\mathrm{pH}$ corrosion $(\mathrm{pH} \sim 2)$ and kept at high overvoltage $(\sim 2 \mathrm{~V})$.

\subsubsection{Seawater Electrolysis}

Water electrolysis systems usually consist of two half-reactions: HER at the cathode and OER at the anode. Compared to the limited pure water, seawater is the most abundant aqueous electrolyte on earth for the utilization in the process of water electrolysis. Seawater electrolysis was investigated by Bennett [93], which was composed of HER at the cathode and chlorine evolution reaction (CIER) at the anode [66]. CIER is a two-electron process, and chlorine or hypochlorite is the value-added product [94]. Four years later, Trasatti used different anodes for seawater electrolysis to investigate the selectivity for anodic process [95]. In 2016, Dionigi et al. proposed the chemical limitations of seawater electrodes and 

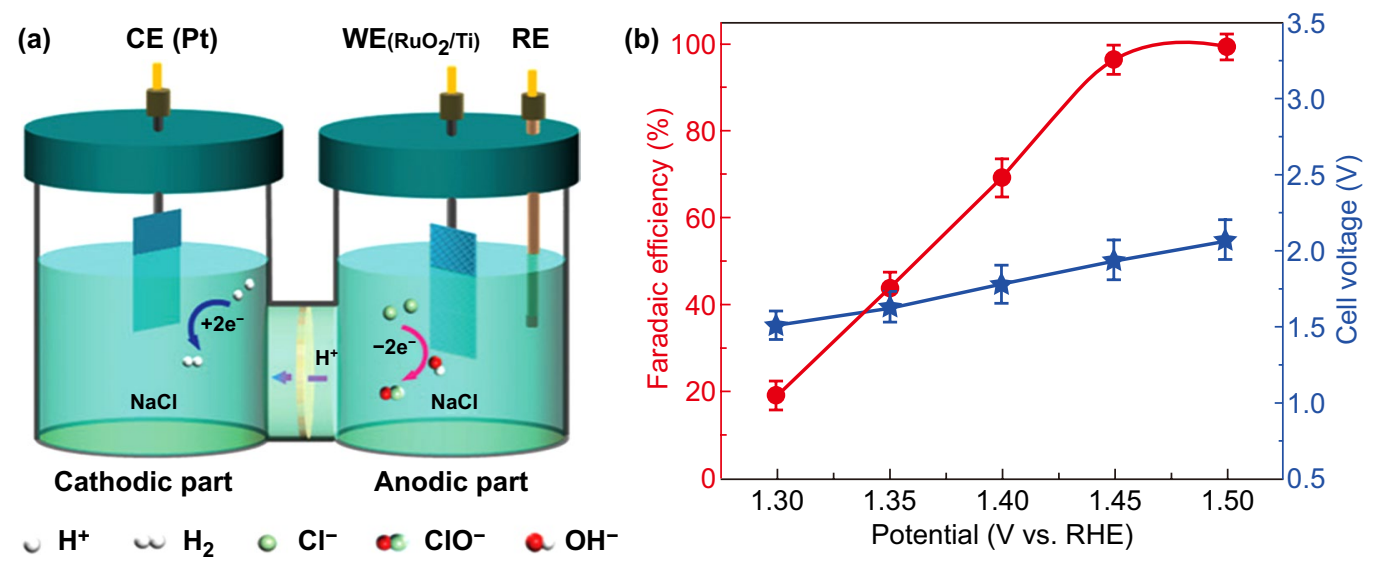

Fig. 7 a Schematic of the electrocatalytic cell for cathodic HER and anodic hypochlorite production, b dependence of the FE of hypochlorite with the applied potentials on the cathode and the cell voltage. Reproduced with permission from Ref. [97]. Copyright 2019 Royal Society of Chemistry

presented the design criterion for selective seawater splitting catalysts [96].

In the seawater electrolysis system, the membrane (such as Zirfon) should be physically robust and insusceptible to blockages, because largely block either anions or cations (such as $\mathrm{H}^{+}, \mathrm{Na}^{+}, \mathrm{OH}^{-}$and $\mathrm{Cl}^{-}$and so on) are able to migrate through the membrane [66]. A commercial ruthenium oxide-coated titanium electrode $\left(\mathrm{RuO}_{2} / \mathrm{Ti}\right)$ and Pt electrode were served as the working electrode and the counter electrode, respectively, to achieve CIER at the anode and HER at the cathode (Fig. 7a). The FE of hypochlorite increased linearly with the applied potential on the anode, which could achieve $99 \%$ at the applied potential of $1.5 \mathrm{~V}$ vs. RHE on the $\mathrm{RuO}_{2} / \mathrm{Ti}$ electrode (Fig. 7b) [97].

\section{Water Splitting Driven by a Photoelectrode Device}

Electrolyzed water can effectively generate $\mathrm{H}_{2}$ through a two-electrode system. However, it takes a large amount of electrical energy to conquer the thermodynamic barrier in the electrolysis of water. In the photoelectrochemical (PEC) electrolysis cell [98, 99], the photoanode absorbs the solar energy to generate the photovoltage to effectively drive water splitting, which can effectively decrease the external energy consumption [100-102]. To minimized utilization of the external energy consumption and realize unassisted overall light-induced water splitting, a possible way is using a tandem structure to generate a total photovoltage through complementary light absorption between different semiconductor electrodes [103-113].

Mathews et al. constructed that a $\mathrm{Fe}_{2} \mathrm{O}_{3}$ photoanode in tandem with an organic-inorganic $\mathrm{CH}_{3} \mathrm{NH}_{3} \mathrm{PbI}_{3}$ perovskite solar cell (PSC) (Fig. 8a) could achieve overall unassisted water splitting at air mass 1.5 global (AM 1.5G) irradiation with a solar-to-hydrogen (STH) conversion efficiency of $2.4 \%$. The total potential produced by this tandem system reached to $1.87 \mathrm{~V}$, which was surpassed the required thermodynamic and kinetic potential of $1.6 \mathrm{~V}$, delivering water splitting with no external energy consumption [114]. Jun and Lee et al. reported that cobalt carbonatecatalyzed, $\mathrm{H}$ and 3 at\% Mo dual-doped $\mathrm{BiVO}_{4}(\mathrm{Co}-\mathrm{Ci} / \mathrm{H}$, $3 \% \mathrm{Mo}: \mathrm{BiVO}_{4}$ ) device in series with $\mathrm{CH}_{3} \mathrm{NH}_{3} \mathrm{PbI}_{3}$ singlejunction PSC could realize wireless solar water splitting under AM 1.5G without external energy supply (Fig. 8b). The STH efficiency of the device exhibited STH efficiency was $3.0 \%$, which could be even higher along with the improvement of the photoanode performance [115]. Luo et al. reported that a semilucent $\mathrm{CH}_{3} \mathrm{NH}_{3} \mathrm{PbBr}_{3} \mathrm{PSC}$ as the top absorber pairing with a $\mathrm{CuIn}_{x} \mathrm{Ga}_{1-x} \mathrm{Se}_{2}$ (CIGS) multilayer photocathode as the bottom absorber could panchromatic harvest of the solar spectrum for effective overall water splitting (Fig. 8c). For this PV-PEC system employing a single-junction PSC as the bias source at AM $1.5 \mathrm{G}$ irradiation, a STH efficiency was reached to over $6 \%$. Moreover, the efficiency could attain over $20 \%$ by further 


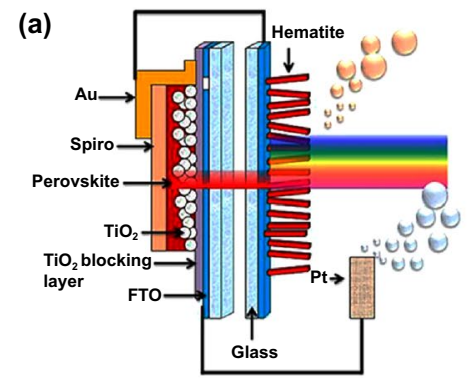

(b)

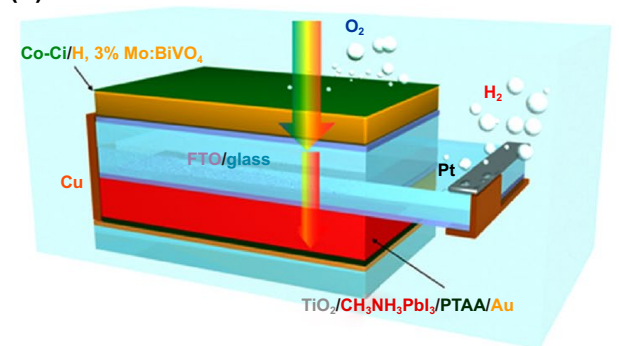

(d)

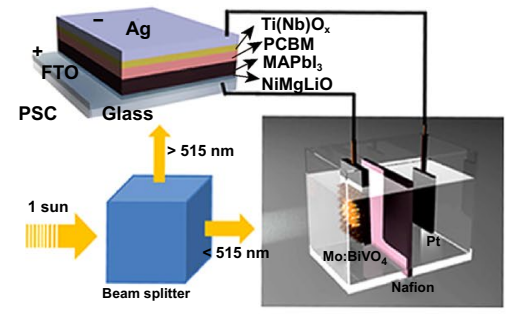

(e)

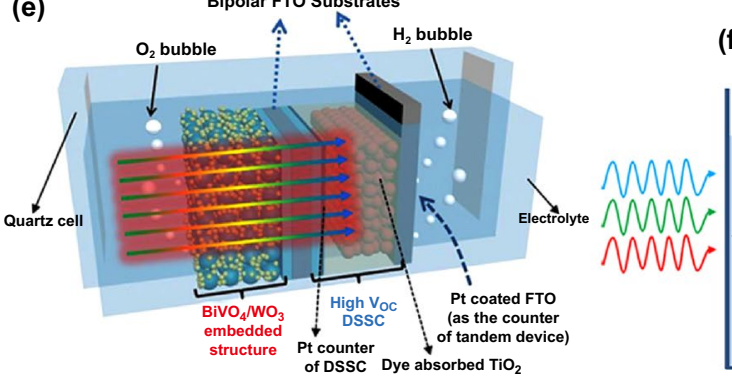

(c)

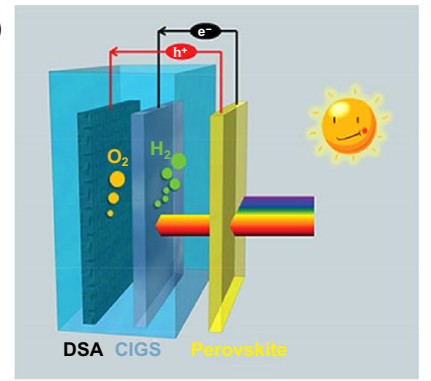

(f)

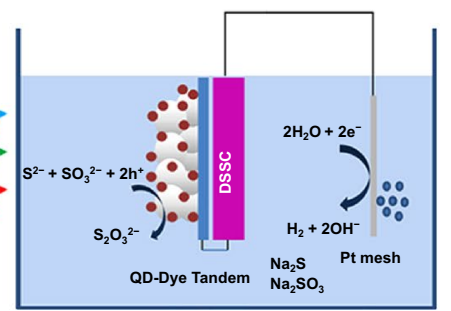

Fig. 8 a Schematic of the dual-junction PSC/hematite photoanode tandem cell. Reproduced with permission from Ref. [114]. Copyright 2015 American Chemical Society, b configuration consisted of $\mathrm{Co}-\mathrm{Ci} / \mathrm{H}, 3 \% \mathrm{Mo}: \mathrm{BiVO}_{4}$ and $\mathrm{TiO}_{2} / \mathrm{CH}_{3} \mathrm{NH}_{3} \mathrm{PbI}_{3}$ tandem cell. Reproduced with permission from Ref. [115]. Copyright 2015 American Chemical Society, c schematic of the perovskite and CIGS tandem water splitting cell. Reproduced with permission from Ref. [116]. Copyright 2015 John Wiley and Sons, d the configuration of the PEC-PSC tandem device. Reproduced with permission from Ref. [117]. Copyright 2016 American Association for the Advancement of Science, e schematic of the WO $\mathrm{WiVO}_{4}$ photoanode tandem configuration. Reproduced with permission from Ref. [120]. Copyright 2015 Elsevier Inc., f scheme of the PEC-DSSC tandem cell. Reproduced with permission from Ref. [121]. Copyright 2013 American Chemical Society

optimizing the performance of the perovskite top absorber [116]. Qiu et al. constructed a single PSC in tandem with nanoporous Mo-doped $\mathrm{BiVO}_{4}\left(\mathrm{Mo}: \mathrm{BiVO}_{4}\right)$ photoanode PEC cell device by using a beam splitter to divide a standard sunlight beam into two light beams (Fig. 8d). The PSC-PEC serial system achieved unassisted water splitting with a STH efficiency of $6.2 \%$ and long-term stability over $10 \mathrm{~h}$ (only 5.8\% decay) [117].

Owing to the energy supply is efficient and the materials (e.g., $\mathrm{TiO}_{2}$ ) are cheap, abundant and environmentally friendly, dye-sensitized solar cell (DSSC) in tandem with photoelectrodes are prospective system for unassisted water splitting [118]. Herein, Sivula et al. constructed a device based on an oxide $\left(\mathrm{WO}_{3}\right.$ or $\left.\mathrm{Fe}_{2} \mathrm{O}_{3}\right)$ photoanode in series with a DSSC for unassisted water splitting. In this device, the light was incident on the photoanode before the underlying DSSC. The $\mathrm{WO}_{3} / \mathrm{DSSC}$ serial system reached a STH conversion efficiency of $3.10 \%$, while that of $1.17 \%$ in the $\mathrm{Fe}_{2} \mathrm{O}_{3} / \mathrm{DSSC}$ tandem device. For the two tandem cells, the optical transmittances and spectral responses matched with the bandgaps of oxide, determining the photocurrent and performance of devices. The performance of $\mathrm{Fe}_{2} \mathrm{O}_{3} / \mathrm{DSSC}$
PEC tandem cells was retained $80 \%$ after more than $8 \mathrm{~h}$, which attributed to the degradation of DSSC. Therefore, the layout relied on chosen redox mediators and catalysts for the DSSC and photoanodes, respectively [119]. Wang and Park et al. demonstrated a 5.7\% STH without any external bias unassisted monolithic tandem system, which was combined the high transparency of $\mathrm{BiVO}_{4}$-sensitized mesoporous $\mathrm{WO}_{3}$ films/Pt with a single DSSC (Fig. 8e). On one hand, the $\mathrm{BiVO}_{4}$ coating on the porous $\mathrm{WO}_{3}$ films maintained the high transparency, allowing enough photons to enter the dye-sensitized photoanode. On the other hand, the porphyrin-dyesensitized photoanode with a cobalt electrolyte produced enough potential to achieve wireless solar water splitting in the tandem system [120]. Mora-Sero and Gimenez et al. established a tandem device combined a CdS quantum dots modified $\mathrm{TiO}_{2}$ photoanode connected with a DSSC for water splitting with no external bias (Fig. 8f). This device showed a STH conversion efficiency of around $0.78 \%$ and high stability. Designing hybrid photoanodes with different light absorbers was important for developing efficient water splitting devices [121]. 


\section{Water Splitting Driven by Solar Cells}

As energy storage systems, solar cells, including Si solar cells, CIGS solar cells, PSCs, organic solar cells (OSCs) and DSSCs [104, 122-124], are able to transform surplus solar energy into storable and distributable energy carriers. The photovoltage of series connected solar cells can drive water electrolysis [125].

\subsection{By Conventional Solar Cells}

For photovoltaic (PV)-driven water splitting, several connected crystalline conventional solar cells (such as $\mathrm{Si}$ and CIGS solar cells) are prospective because of the high STH efficiency and solar-driven durability for $\mathrm{H}_{2}$ production [60, 104, 126].

Gan and Zhang et al. proposed a bimetallic compound $\mathrm{NiFeSP}$ on the commercial NF (NiFeSP/NF) in series with a Si solar cell to implement overall water splitting (Fig. 9a). The voltage of combination of the Si solar cell and the bifunctional $\mathrm{NiFeSP} / \mathrm{NF}$ electrodes for water splitting in the tandem system was $1.58 \mathrm{~V}$ to reach a current density of $10 \mathrm{~mA} \mathrm{~cm}{ }^{-2}$, corresponding to a STH conversion efficiency of $\sim 9.2 \%$ [127]. Shen et al. also reported that three Si solar cells in series (entire area of $3 \mathrm{~cm}^{2}$ ) were combined with the double-layer Ni-Co-S/Ni-Co-P electrocatalyst on $\mathrm{NF}$ (NCS/NCP/NF) electrodes for unassisted water splitting (Fig. 9b). When using NCS/NCP/NF as a bifunctional catalyst for water splitting, the current density of $10 \mathrm{~mA} \mathrm{~cm}^{-2}$ can be obtained with only $1.49 \mathrm{~V}$. Finally, the whole solar water splitting was realized with the efficiency of STH reached to $10.8 \%$ [122]. Oh, Ryu and Kim et al. combined four $\mathrm{Si}$ heterojunction solar cells in series with a bifunctional NiFe nanostructures electrocatalyst to realize water splitting (Fig. 9c). The overpotential of NiFe inverse opal electrolyzer for water splitting was $\sim 160 \mathrm{mV}$, achieving a STH conversion efficiency of $9.54 \%$ more than $24 \mathrm{~h}$ with no bias condition [128].

Compared to Si solar cell, the outstanding advantage of CIGS is that the band gap energy can be modulated to effectively absorb the solar spectrum, so it is also widely used to achieve water splitting [129-131]. For purpose of overcoming the problem of low energy to drive overall water splitting, connected series into a monolithic device can be
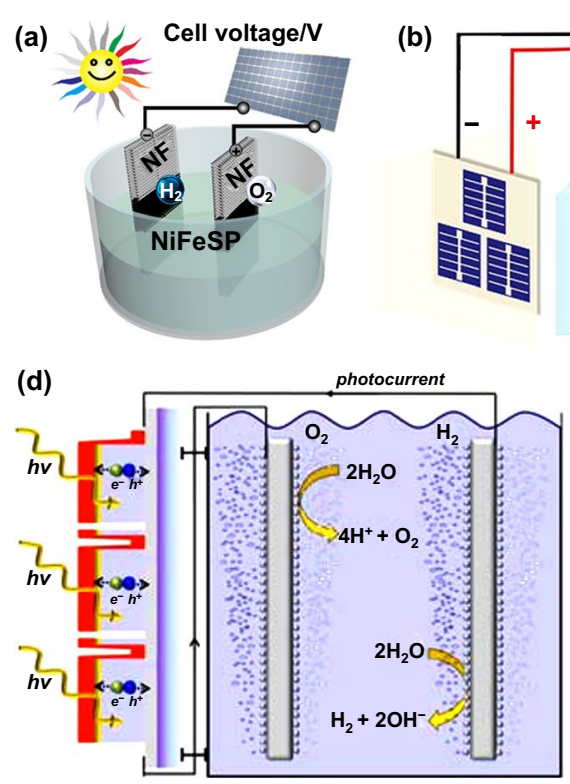

(b)

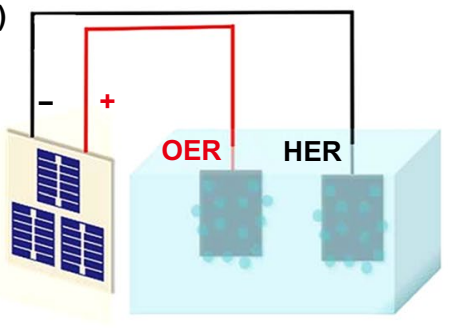

(e)
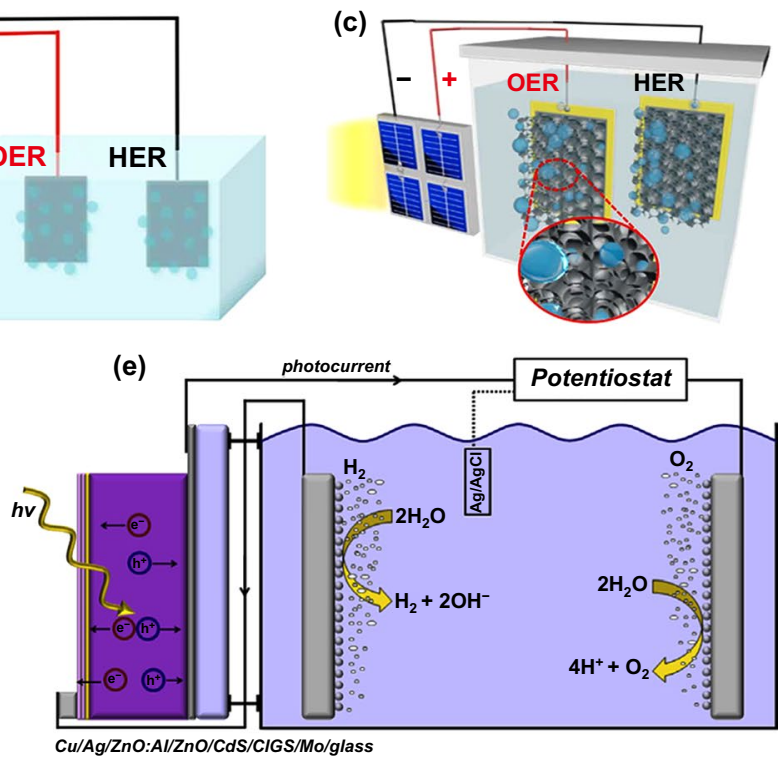

Fig. 9 a Schematic diagram of the solar-driven system with a Si solar cell for overall water splitting. Reproduced with permission from Ref. [127]. Copyright 2017 American Chemical Society, b unassisted water splitting using NCS/NCP/NF as the electrodes and Si solar cells as the light absorber. Reproduced with permission from Ref. [122]. Copyright 2018 Royal Society of Chemistry, $\mathbf{c}$ unassisted water splitting by using a combination of an NiFe electrolyzer and Si solar cells. Reproduced with permission from Ref. [128]. Copyright 2017 Elsevier Inc., d schematic diagram of the CIGS absorber connected with the catalyst module by wires. Reproduced with permission from Ref. [132]. Copyright 2013 Royal Society of Chemistry, e schematic diagram of the CIGS electrode connected with a working electrode with deposited catalyst in the electrolyte by wires. Reproduced with permission from Ref. [133]. Copyright 2013 Elsevier Inc 
adopted to supply enough to drive the whole reaction. For example, Jacobsson et al. reported that three series-interconnected compound semiconductor CIGS PV electrolysis could efficiently realize solar water splitting at AM 1.5G irradiation (Fig. 9d). The current density was centered at $8.5 \mathrm{~mA} \mathrm{~cm} \mathrm{~cm}^{-2}$ and a STH conversion efficiency reached to $10.5 \%$ [132]. Jacobsson et al. demonstrated CIGS solar cell could be applied to water splitting into $\mathrm{H}_{2}$. They used a $p-n$ junction for separating the charge and a catalyst deposited on the surface to significantly improve the performance in the configuration of a PEC cell (Fig. 9e). In this device, the efficient charge separation production from the catalysis improved the durability of CIGS in the light irradiation. Furthermore, photocurrents in this device could reach to over $20 \mathrm{~mA} \mathrm{~cm}^{-2}$. The full potential of CIGS as a highly

(a)

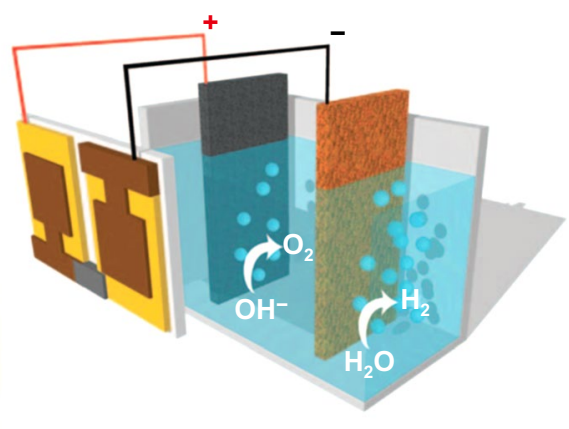

(c)

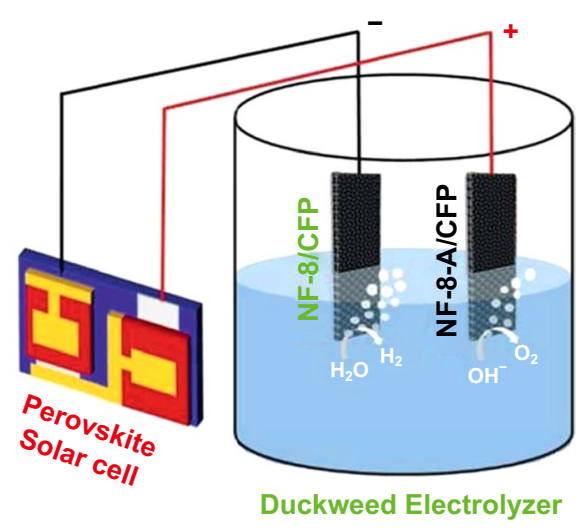

efficient absorbent material for water cracking was demonstrated. They confirmed the full potential of CIGS as a highly effective absorbent material could be used for water splitting [133].

\subsection{By Perovskite Solar Cells}

In the above tandem system for water splitting in Sect. 4.1, owing to the low open-circuit voltages of Si solar cells, at least three to four connected cells in series must be utilized to achieve reasonable efficiency. In contrast, PSCs have achieved open-circuit voltages at $0.9 \mathrm{~V}$ and up to $1.5 \mathrm{~V}$ [134-139], which is sufficient for efficient water splitting by connecting just two in series [123]. Grätzel reported that the tandem PSC could be used to drive electrolytic

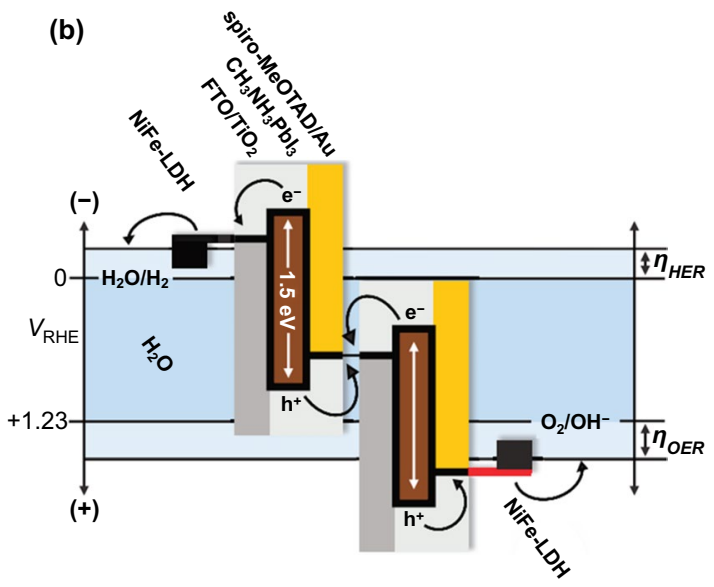

(d)

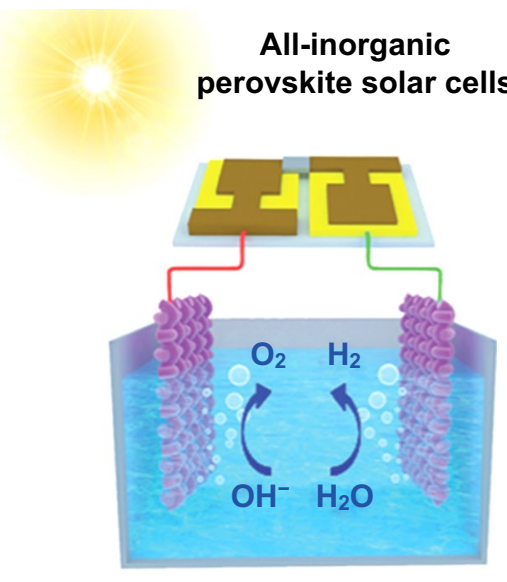

Fig. 10 a Schematic diagram and $\mathbf{b}$ a generalized energy of the tandem PSC for water splitting. Reproduced with permission from Ref. [140]. Copyright 2014 American Association for the Advancement of Science, $\mathbf{c}$ schematic diagram of the solar energy-driven overall water splitting device with a PSC. Reproduced with permission from Ref. [141]. Copyright 2018 Royal Society of Chemistry, $\mathbf{d}$ configuration of the electrolyzer with the $\mathrm{Ni}_{0.5} \mathrm{Co}_{0.5} \mathrm{P} / \mathrm{CP}$ bifunctional electrocatalyst and all-inorganic PSCs under irradiation. Reproduced with permission from Ref. [123]. Copyright 2018 Royal Society of Chemistry 
splitting of water. The configuration was a water splitting system combing with a solution-processed tandem PSC and $\mathrm{NiFe} \mathrm{LDH}$ used as anode and cathode electrodes in alkaline electrolyte (Fig. 10a, b). A photocurrent density of the tandem two-electrode system was around $10 \mathrm{~mA} \mathrm{~cm}^{-2}$, corresponding to a STH efficiency of $12.3 \%$ [140]. Bhattacharyya et al. developed $\mathrm{NiFe}$-alloy nanoparticles supported by $\mathrm{N}, \mathrm{S}$-doped mesoporous carbon matrix from duckweed as efficient electrocatalysts (Fig. 10c). For overall water splitting, only $1.61 \mathrm{~V}$ was required to attain a current density of $10 \mathrm{~mA} \mathrm{~cm}^{-2}$ for over $200 \mathrm{~h}$. Combining with PSCs, the electrolyzer for overall water splitting showed a STH efficiency of $9.7 \%$, which is completely powered by solar energy [141]. Jin et al. reported that bifunctional bimetallic phosphide $\left(\mathrm{Ni}_{0.5} \mathrm{Co}_{0.5} \mathrm{P} / \mathrm{CP}\right)$ in tandem with all-inorganic PSCs (based on a $\mathrm{CsPb}_{0.9} \mathrm{Sn}_{0.1} \mathrm{IBr}_{2}$ light absorber and a nanocarbon electrode Fig. 10d) realized efficient overall water splitting. The water splitting electrolyzer could achieve a current density of $10 \mathrm{~mA} \mathrm{~cm}{ }^{-2}$ at only $1.61 \mathrm{~V}$. Driven by stabilized allinorganic PSCs, the electrolyzer delivered a STH conversion efficiency of $3.12 \%$ and good durability [123].

\section{Water Splitting Driven by Thermoelectric Device}

Water splitting driven by solar cell is a common energydriven water splitting strategy. However, the utilization efficiency of sunlight by the solar cell is relatively low because solar cells are chiefly effective in the range of ultraviolet and visible light. Conventional semiconductor solar energy conversion technology cannot efficiently utilize the infrared light, which occupies nearly half of the sunlight. The combination of TE device and infrared-active materials supplies a particular approach to transform infrared sunlight to the electricity, which improves the solar energy utilization efficiency [142-147]. Thus, the study of water splitting driven by TE device is extensively performed.

\subsection{By Surface-Modified Thermoelectric Device}

The infrared light usually delivers the energy in the form of heat through photothermal effect [148, 149]. Transforming the released heat into available energy (e.g., electricity) is a distinct method to utilize the infrared light. This conversion can be probable realized by TE device [150-152]. It is a pity that the surface of commercial TE device is unserviceable to absorb the infrared light. In order to improve the efficiency of TE devices, it is necessary to expand the absorption of infrared light by TE devices [151]. This requirement enlightened us to develop the probability of integrating photothermal materials on the TE device to promote the efficiency of photo-thermoelectric conversion [153]. Generally, materials with higher photothermal conversion efficiency include the Group VIII metal materials, graphene oxide (GO) [154], carbon nanomaterials, transition metal oxides (e.g., $\mathrm{MoO}_{2}$, $\mathrm{WO}_{3}, \mathrm{Fe}_{2} \mathrm{O}_{3}$ ) and chalcogenides (e.g., $\mathrm{Cu}_{2} \mathrm{~S}$ ) [155]. In 2014, the photothermal effect of GO had been demonstrated for the first time for TE devices [153]. The GO drop-coated on the surface of the TE device could transform the infrared light to the electricity, which was directly utilized to carry out photoelectrocatalytic process in the case of no applied voltage. As could be seen from the infrared thermal image, the conclusion that the surface coating of GO could significantly increase the response of TE devices can be drawn. Our group employed carbon nanoparticles (CNP) light absorbent layer on the top to increase the absorption efficiency of STEGs. A very easy candle flame preparation method was employed to synthesize the black CNP layer on the hot end of the commercial TE device (CNP generator). The synthesized CNP layer had a $3 \mathrm{D}$ porous structure which was conducive to capture light, and the power produced by this STEG device could drive an electrolyzer for splitting water to produce $\mathrm{H}_{2}$ (Fig. 11a, b). In this water splitting system driven by TE device, 6 sets of CNP coated thermoelectric generator devices were series connection to supply adequate voltage for electrolysis of water. After connecting the TE generator with the electrochemical cell, the cathode and anode immediately generated plenty of bubbles under the sunlight irradiation. The production of $\mathrm{H}_{2}$ and $\mathrm{O}_{2}$ was at an average rate of 20 and $10 \mu \mathrm{mol} \mathrm{h}^{-1}$, respectively, and the rate at the time between 11:40 and 12:40 was highest on account of the maximum sunlight intensity (Fig. 11c). This study demonstrated that the output voltage of TE device was able to drive the $\mathrm{H}_{2}$ production from water splitting by coating nanomaterials with photoabsorbing and photo-to-heat conversion properties on the hot end of TE devices [156]. Inspired by the dual model effects of surface plasmon resonance (SPR) photothermal conversion and efficient electrocatalytic activity for group VIII metals, our group then proposed Ni nanosheets array grown on the surface of TE device for electrolysis of water. In the integrated device, Ni nanosheets array 
(a)

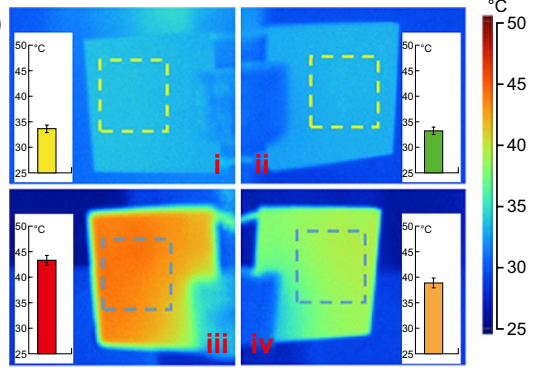

(d)

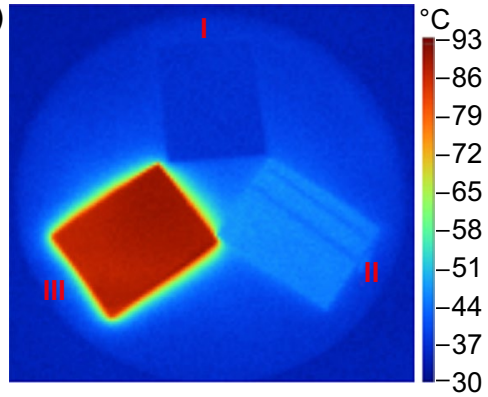

(b)

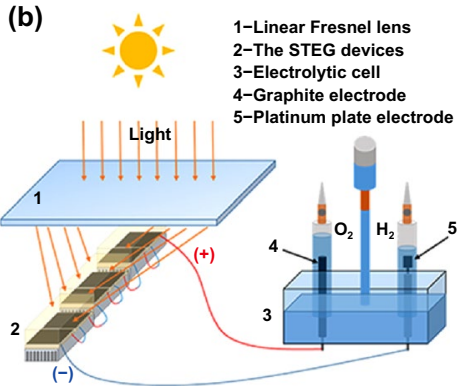

(e)

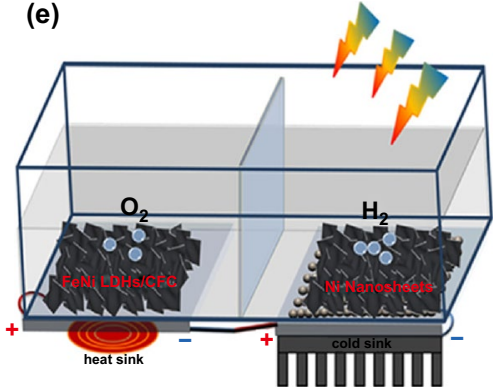

(c)
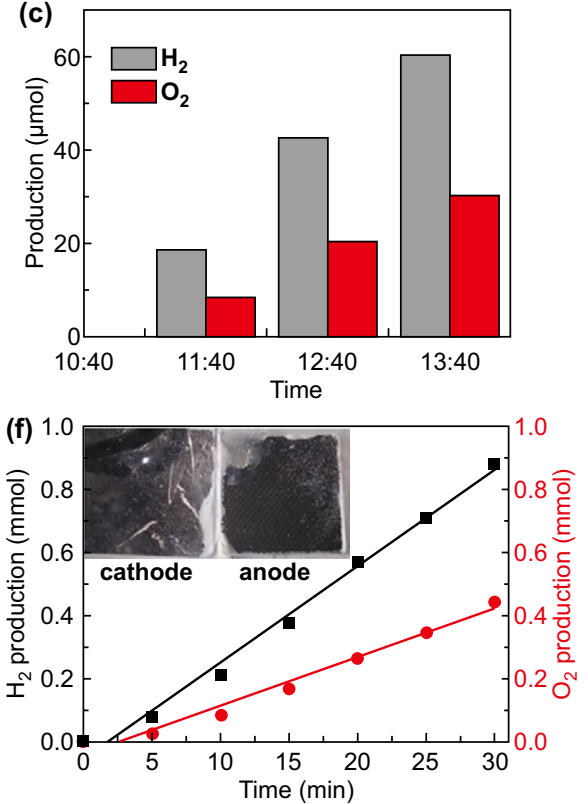

Fig. 11 a Temperature distributions under 1 sun irradiation of: (i) hot side and (ii) cold side of bare generator; (iii) hot side and (iv) cold side of CNP generator. Inserts: temperature statistics of the area in corresponding dotted box, b schematic of the overall water splitting system driven by 6 series-wound STEG devices, c production of $\mathrm{H}_{2}$ and $\mathrm{O}_{2}$ by the water splitting system at different time. Reproduced with permission from Ref. [156]. Copyright 2018 Elsevier Inc., $\mathbf{d}$ the infrared thermal images of $\mathrm{Al}_{2} \mathrm{O}_{3}$ ceramic chip (I) and $\mathrm{Al}_{2} \mathrm{O}_{3}$ ceramic chip with Ni film (II) and $\mathrm{Ni}$ nanosheets/Ni film (III), e illustration of electrolyzer-TE hybrid device, $\mathbf{f} \mathrm{H}_{2} / \mathrm{O}_{2}$ production versus time curve of electrolyzer-TE hybrid device with additional $0.7 \mathrm{~V}$ applied voltage. Reproduced with permission from Ref. [157]. Copyright 2019 Elsevier Inc

was served as electrocatalysts and light absorption layer. Replacing the conventional power supply, the output voltage of this integrated system could be immediately applied for electrolysis of water. It was demonstrated that the $\mathrm{Ni}$ nanosheets array was utilized as an effective photothermal conversion layer to generate temperature difference $(\Delta T)$ for TE, and as an efficient electrocatalysts for HER (Fig. 11d, e). The electrolyzer-TE complex devices were constructed for overall water splitting in a two-electrode system, with a $\mathrm{H}_{2}$ and $\mathrm{O}_{2}$ production rate of 1.818 and $0.912 \mathrm{mmol} \mathrm{h}^{-1}$, respectively (Fig. 11f). The integrated TE device provided great advantages for constructing the water splitting system, which were conducive to utilize the solar thermal energy and the waste heat in the prospective applications [157].

\subsection{By Integrated Photoelectrochemical-Thermoelectric Device}

The parameters that effect TE conversion efficiency are the Seebeck coefficient (or thermopower), the electrical conductivity and the thermal conductivity [158]. Considering these factors, the energy conversion efficiency of TE device (5-10\%) is low, compared to PVs (up to 46\%) [159]. Therefore, several researches have demonstrated that by combing TE and PEC reaction, the utilization efficiency for both solar energy harvest and water splitting can reach a high content [160]. The first proposed the combination of PEC and photothermal-electrochemical cycles for $\mathrm{H}_{2}$ production by solar energy was by Nikola Getoff in 1984 [161], which was in acid aqueous solution using $\mathrm{I}_{2}$ and $\mathrm{I}_{3}{ }^{-}$acting as a sensitizer with the existence of ferrous ions. With the introduction of the TE device, the unabsorbed light was collected to provide heat for partly converting into electricity by the TE device. Hence, the efficiency of $\mathrm{H}_{2}$ production increased of $30 \%$ compared with that of single PEC cycle. However, no research for photothermal-electrochemical water splitting was conducted for a long time since then, until 2015, Lee's group $[126,162]$ continuously published two articles to study the integrated PEC-TE device for water splitting by using 

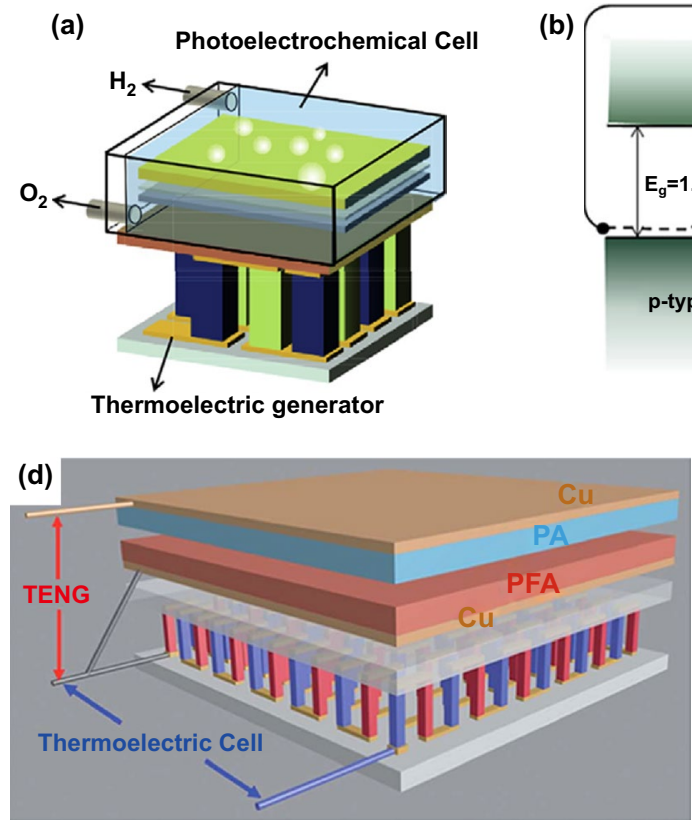

(b)

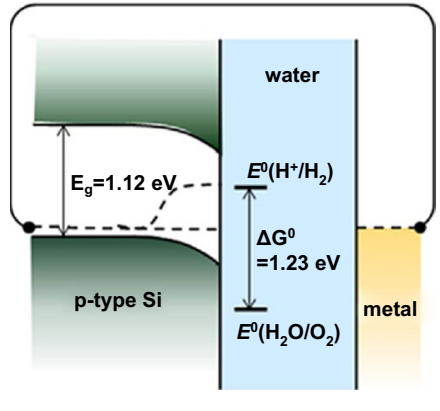

(e)

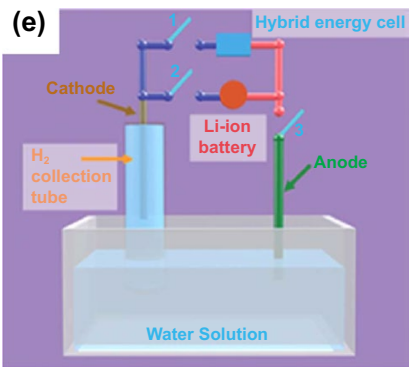

(c)

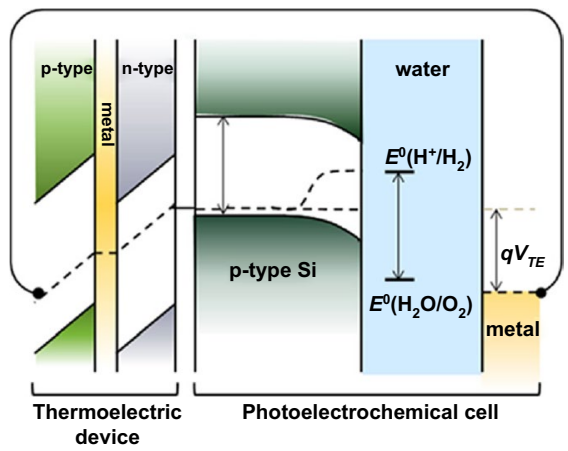

(f) 0.

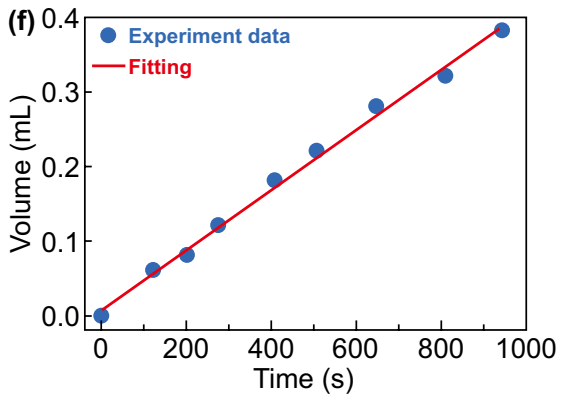

Fig. 12 a Schematic diagram of a PEC-TE hybrid device. Energy band diagrams of $\mathbf{b}$ sole PEC and $\mathbf{c}$ a PEC-TE hybrid circuit under illumination depicting the influence of $q V_{\mathrm{TE}}$. Reproduced with permission from Ref. [162]. Copyright 2015 Elsevier Inc., $\mathbf{d}$ schematic diagram of the fabricated TENG-TE hybrid energy cell, e schematic diagram of the self-powered system for water splitting to produce $\mathrm{H}_{2}$, $\mathbf{f}$ produced volume of $\mathrm{H}_{2}$ at different working times. Reproduced with permission from Ref. [164]. Copyright 2013 Royal Society of Chemistry

solar energy and waste heat energy to generate storable and transportable $\mathrm{H}_{2}$ fuel. By using the hybrid water splitting device water splitting system, the power generation for $\mathrm{H}_{2}$ evolution of $55 \mathrm{~mW} \mathrm{~cm} \mathrm{~cm}^{-2}$ was achieved, which was almost 4 times higher than that of a sole PEC cell. According to the total charge transferred, the measured volume of $\mathrm{H}_{2}$ was well consistent with the theoretical value of $100 \%$ Faraday efficiency (FE), indicating that the generated charge was completely involved in promoting $\mathrm{H}_{2}$ evolution. Furthermore, this hybrid operation did not need to use noble metals (e.g., platinum or iridium) because the thermovoltage sole could counteract the kinetic overpotential [126]. Meanwhile, the author explained the enhancement of water splitting in terms of adjusting the Fermi level of the counter electrode with $\Delta T$ (Fig. 12a-c). As we all known, band edge potentials of semiconductors must straddle the redox potentials of $\mathrm{H}_{2}$ and $\mathrm{O}_{2}$ for full PEC operation without external bias. However, since the minimum valence band of silicon was not enough positive to oxidize water, silicon was not suitable as a semiconductor material for spontaneous water splitting (Fig. 12b) [162]. Thus, since a TE device was concatenated to a PEC cell, the Fermi level of counter electrode could be adjusted by the applied $\mathrm{V}_{\mathrm{TE}}$. When the working electrode ( $\mathrm{p}-\mathrm{Si}$ ) and counter electrode $(\mathrm{Pt})$ were linked to the positive and negative terminal of the TE device, respectively, electrons injected from the Pt counter electrode flew through the wire to the anode of the TE device. It was worth noting that the Fermi energy level moved downward to a more positive potential until the Fermi energy level of Pt was in alignment with that of the TE device (Fig. 12c). Since the Fermi level of the metal was lower than the oxidation potential of the water, the water would spontaneously oxidize under the action of the $V_{\mathrm{TE}}$ [162]. Wang et al. proposed a novel PV-TE hybrid device consisted of a serial DSSC, a solar selective absorber (SSA) and a TE generator, providing some inspiration for the development of high-performance PV-TE hybrid devices. The author proposed that the sunlight could be separated into two beams, and UV-visible light was absorbed by a solar cell and infrared light was absorbed by a TE generator to convert into electricity in this hybrid device, which improve the overall conversion efficiency greater than $13 \%$. And thereafter, water splitting driven by TE device integrated 
PV cell or other electric generation system was widely studied by researchers [163]. Wang's group manufactured a hybrid energy cell integrated by a TENG, a solar cell and a TE device, which could be utilized for concurrently/separately harvesting mechanical, solar and/or thermal energies. The output power of the hybrid energy cell could be immediately utilized to split water with no external power supply (Fig. 12d-f). The volume of the $\mathrm{H}_{2}$ production was linearly related to the splitting time at a generating rate of $4 \times 10^{-4} \mathrm{~mL} \mathrm{~s}^{-1}$ (Fig. 12f). As shown in Fig. 12e, there were two ways to water splitting. After the point " 1 " was concatenated to the point " 3 ," this hybrid energy cell could be immediately utilized for water splitting, in which the solar cell is in parallel with the rectified TENG. For another way, after the point " 1 " connecting to the point " 2 ," the generated energy could be stored in the Li-ion battery and then utilized for electrolysis of water [164].

Intensive research has been conducted to combine PEC cell and TE device for improved solar $\mathrm{H}_{2}$ production. However, all of these studies adopt the strategy of connecting PV cells, TE devices and water splitting electrodes together in series. The resulting structure is very complex and not integrated. Therefore, it is a qualitative leap to study how to realize the integration of photodriving components and water splitting components, no matter for effective use of solar energy or for water splitting. The research for integrated device will offer enormous advantages in the aspect of designing the overall water splitting system with integrated structure which are conducive to the practical applications. In addition, the development of an excellent hybrid device which can realize long-term durability of solar water splitting will also become a top priority in the further studies.

\section{Water Splitting Driven by a Triboelectric Nanogenerator}

As depicted in Sects. 4 and 5, water splitting driven by a hybrid energy cell including a PV cell or a TE cell (Fig. 12) paves the way for water splitting driven by other energy devices. Ever since the discovery of TENG by Wang's group in 2012, TENG had been utilized as an external power supply for water splitting $[165,166]$. In terms of energy conversion of TENG, the transfer of contact-induced charges between two triboelectric materials with opposite polarity produced a potential difference during the separation of them
[167-171]. Then the produced potential difference would prompt the flow of electrons/ions in the external circuit; hence, it could be utilized as power source [168, 172-178]. In 2014, Tang et al. [172] developed a self-powered hybrid system by combining a water-driven TENG with a water splitting cell (Fig. 13a). The circuit diagram of the splitting system and the structure of disk TENG are shown in Fig. 13b. When the rotated speed of the assembled TENG was $600 \mathrm{rpm}$, the formation rate of $\mathrm{H}_{2}$ in the system reached to $6.25 \times 10^{-3} \mathrm{~mL} \mathrm{~min}^{-1}$ in the $30 \mathrm{wt} \% \mathrm{KOH}$ solution. This research provided a strategy of TENG-driven water splitting for $\mathrm{H}_{2}$ generation without external power source. In 2017, the same group prepared a connected TENG-PEC hybrid cell based on $\mathrm{TiO}_{2}$ photoanode, utilizing a flexible TENG to collect environmental dynamic energy, and then charging the Li-ion battery to drive water splitting (Fig. 13c, d) [173]. In the meanwhile, this research proved that the electric field provided by TENG-charged battery played an important role in electrolysis, as well as improved the utilization efficiency of solar energy by boosting the photocurrent (Fig. 13e). Therefore, the TENG-PEC hybrid cell provided an easy and effective method to synergistically transform mechanical and solar energy into chemical energy. Coincidentally, Zhong et al. also developed a self-powered PEC water decomposition system that was combined with a rotatory disk-shaped TENG (RD-TENG), while a titanium modified hematite $\left(\mathrm{Ti}-\mathrm{Fe}_{2} \mathrm{O}_{3}\right.$ ) was used as the photoanode [168]. It is noted that different rotation speed of TENG had different effects on the output peak current change under illumination and in dark. When at a low rotation speed, the peak current under illumination prominently increased in comparison with that in the dark, while no significant variety at a high rotation speed, indicating the direct electrolysis of water at a high speed.

Besides the water-driven TENG, wind-driven TENG was also widely investigated [179-183]. For example, Fan et al. demonstrated a coaxial rotatory freestanding TENG (CRF-TENG) for collecting wind energy using electrospinning polyvinylidene fluoride (PVDF) nanofiber membrane as triboelectric material (Fig. 14a-c) [12]. And on this basis, a fully self-powered system based on CRF-TENG for water splitting to produce $\mathrm{H}_{2}$ was proposed. When the wind speed was $10 \mathrm{~m} \mathrm{~s}^{-1}$, the $\mathrm{H}_{2}$ production rate reached $6.9685 \mu \mathrm{L} \mathrm{min}^{-1}$ in $1.0 \mathrm{M} \mathrm{KOH}$ solution (Fig. 14d, e). 

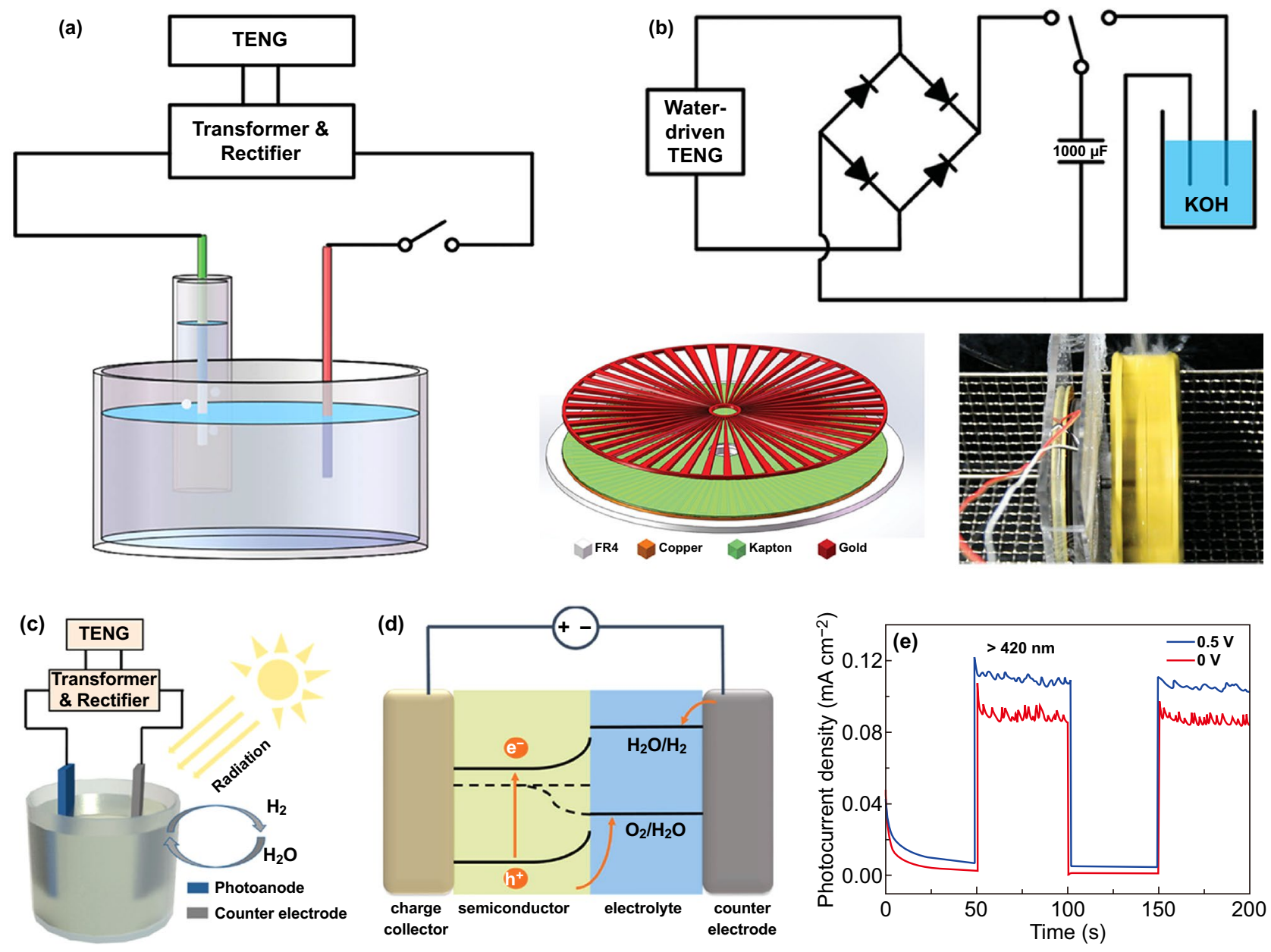

Fig. 13 a Schematic diagram of the TENG-driven water splitting system, b the circuit diagram of the splitting system and the structure of disk TENG. Reproduced with permission from Ref. [172]. Copyright 2014 John Wiley and Sons, c schematic diagram of the TENG-PEC hybrid cells, $\mathbf{d}$ illustration of simplified energy diagram for n-type semiconductor-based solar water splitting, e photocurrent of as-prepared Au-decorated $\mathrm{TiO}_{2}$ with different bias. Reproduced with permission from Ref. [173]. Copyright 2017 John Wiley and Sons

\section{Water Splitting Driven by Other Devices}

Recently, water splitting driven by pyroelectric element attracts much attention for it provides an alternative approach to generate $\mathrm{H}_{2}$ from instantaneous low-grade waste heat or natural temperature variations [184-188]. For instance, Xie and Brown et al. proposed to apply pyroelectric effect to produce a large enough electric potential between two electrodes for water splitting into $\mathrm{H}_{2}$ and $\mathrm{O}_{2}$ gas. The materials utilized in the pyroelectric water splitting system were lead zirconate titanate (PZT-5H) and PVDF thin film [184]. Zhang et al. proposed a pyroelectric water splitting system by utilizing bulk lead PZT as an external charge supply that underwent hot-cold thermal cycles. The schematic diagram of the device was utilized to realize the water splitting with the externally positioned pyroelectric materials (Fig. 15a). As known, the change of ferroelectric polarization with time during thermal cycling was the driving force for the generation of pyroelectric charge during hot-cold fluctuations. Thus, the influences of the electrolyte concentration and heating-cooling frequency on the performance of pyroelectric $\mathrm{H}_{2}$ generation were studied (Fig. 15b-d). As demonstrated, the thickness and the area of PZT sheet played an important role in driving water splitting, where the thickness could be used to guarantee an enough potential to initiate water splitting and the area should be maximized to collect the maximal amount of available surface charge [185]. Therefore, future 

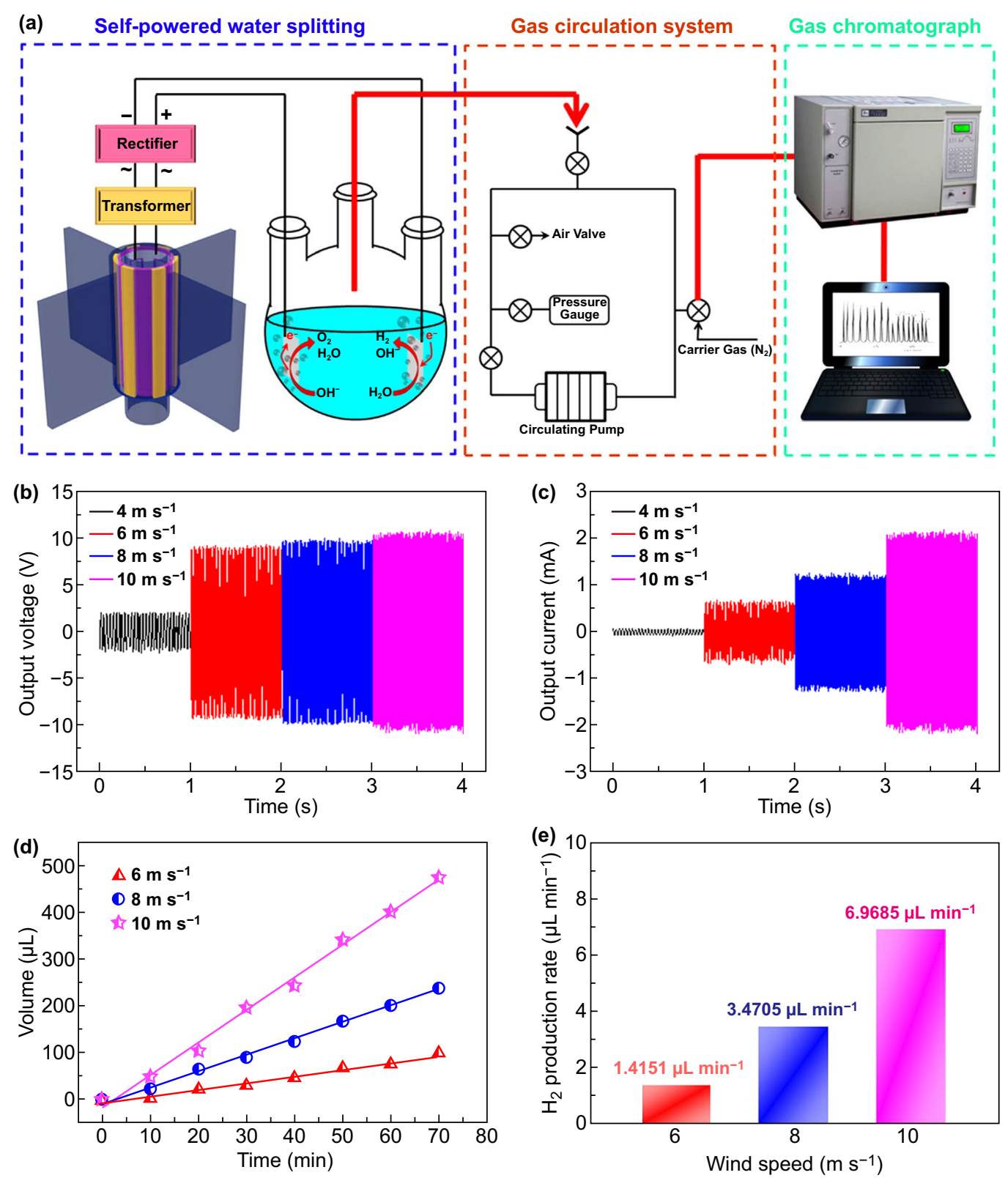

Fig. 14 a Schematic diagram of CRF-TENG wind energy harvester driven self-powered water splitting system, $\mathbf{b}$ the output voltage and $\mathbf{c}$ the output current of the CRF-TENG wind energy harvester with a transformer at different wind speeds, $\mathbf{d} \mathrm{H}_{2}$ production volume as a function of the work times, $\mathbf{e} \mathrm{H}_{2}$ production rate of the CRF-TENG with transformer at different wind speeds. Reproduced with permission from Ref. [12]. Copyright 2018 Elsevier Inc

work could concentrate on the formation of pyroelectric nanostructures to enlarge the surface area of the pyroelectric element or exploring the high heat transfer rates of other pyroelectric materials to increase the magnitude and speed of temperature changes [189-192].

WGS reaction was a main way for industrial $\mathrm{H}_{2}$ production [193-199]. For the traditional WGS reaction, high temperatures and high pressures were essential, and $\mathrm{H}_{2}$ contamination containing $\mathrm{CO}_{2}, \mathrm{CH}_{4}$ and residual $\mathrm{CO}$ was inevitable [200-204]. Herein, Bao et al. reported a novel electrochemical water-gas shift (EWGS) process for directly producing $\mathrm{H}_{2}$ with the purity of over $99.99 \%$ and the FE of approximately $100 \%$ under mild conditions. In contrast to the electrocatalytic water splitting, this WGS 

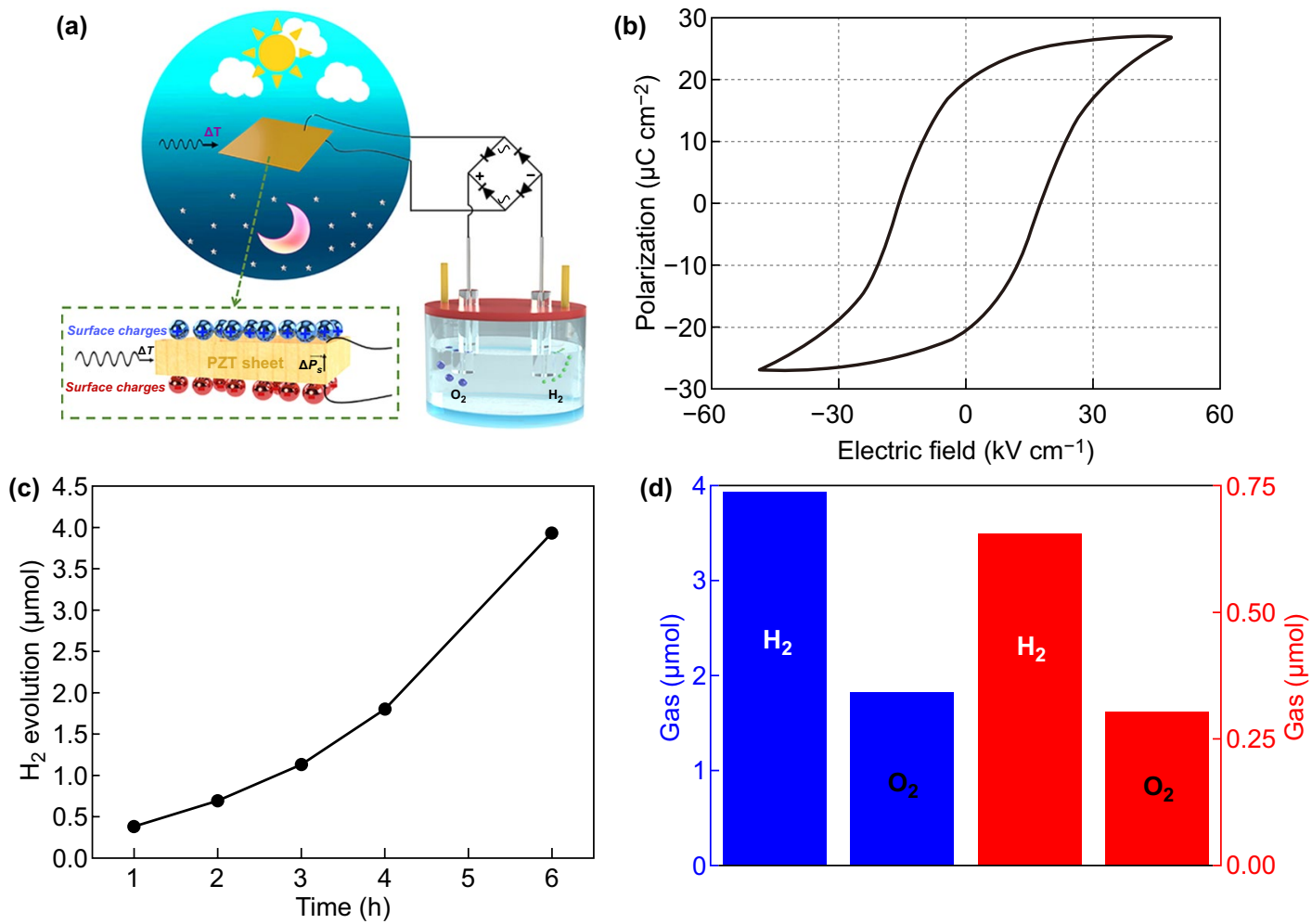

Fig. 15 a Schematic of pyroelectric as an external source for water splitting, $\mathbf{b}$ polarization-electric field loop of PZT sheet and schematic of the surface pyroelectric charges, $\mathbf{c ~} \mathrm{H}_{2}$ evolution from external pyroelectric water splitting with working time from 1 to $6 \mathrm{~h}$, $\mathbf{d}$ the amount and evolution rate of $\mathrm{H}_{2}$ and $\mathrm{O}_{2}$ after $6 \mathrm{~h}$ detected from the gas chromatography. Reproduced with permission from Ref. [185]. Copyright 2020 Elsevier Inc

reaction afforded a promising alternative way to produce with very low operating voltage, which was realized by the rational design of electrolytic cell and electrocatalysts. In the WGS reaction process of electrolytic cell, $\mathrm{CO}$ was oxidized on the anode and $\mathrm{H}_{2}$ was produced from $\mathrm{H}_{2} \mathrm{O}$ reduction on the cathode (Fig. 16a). Meanwhile, anion exchange membrane was used to separate the cathode and anode, maintain the balance of electrolyte ion concentration and prevent the cross-contamination of the anodic $\left(\mathrm{CO}_{2}\right)$ and cathodic $\left(\mathrm{H}_{2}\right)$ reaction products in the system. Through optimization of the anode structure by the hydrophobic PTFE layer on catalyst and design of the anode $\mathrm{Pt}_{3} \mathrm{Cu}$ catalyst, the water-free compartments at the interface of PTFE and catalyst to facilitate the diffusion of $\mathrm{CO}$ and weaken interaction between $\mathrm{CO}$ and anode catalyst surface by $\mathrm{Cu}$ were performed (Fig. 16b-d). Finally, directly producing $\mathrm{H}_{2}$ with the purity of over $99.99 \%$ and the FE of approximately $100 \%$ under mild conditions by this novel electrolytic cell was realized [205].
Anode: $\mathrm{CO}+4 \mathrm{OH}^{-} \rightarrow \mathrm{CO}_{3}^{2-}+2 \mathrm{H}_{2} \mathrm{O}+2 e^{-}$

Cathode: $2 \mathrm{H}_{2} \mathrm{O}+2 e^{-} \rightarrow \mathrm{H}_{2}+2 \mathrm{OH}^{-}$

Total: $\mathrm{CO}+2 \mathrm{OH}^{-} \rightarrow \mathrm{H}_{2}+\mathrm{CO}_{3}^{2-}$

\section{Outlook and Future Challenges}

$\mathrm{H}_{2}$ is one of the most sustainable and environmental-friendly energies for replacing fossil fuel energy to mitigate the growing serious energy crisis. In this review, a variety of green energy systems developed for efficient $\mathrm{H}_{2}$ production are summarized. The matured two-electrode electrolysis of water system can realize overall water splitting with a high performance at a low cell voltage and long-term stabilities, due to the massive efforts on designing and developing of the bifunctional electrocatalysts with excellent electrocatalytic performance. And many green systems containing photoelectrodes, solar cells, TE devices, TENG devices, 

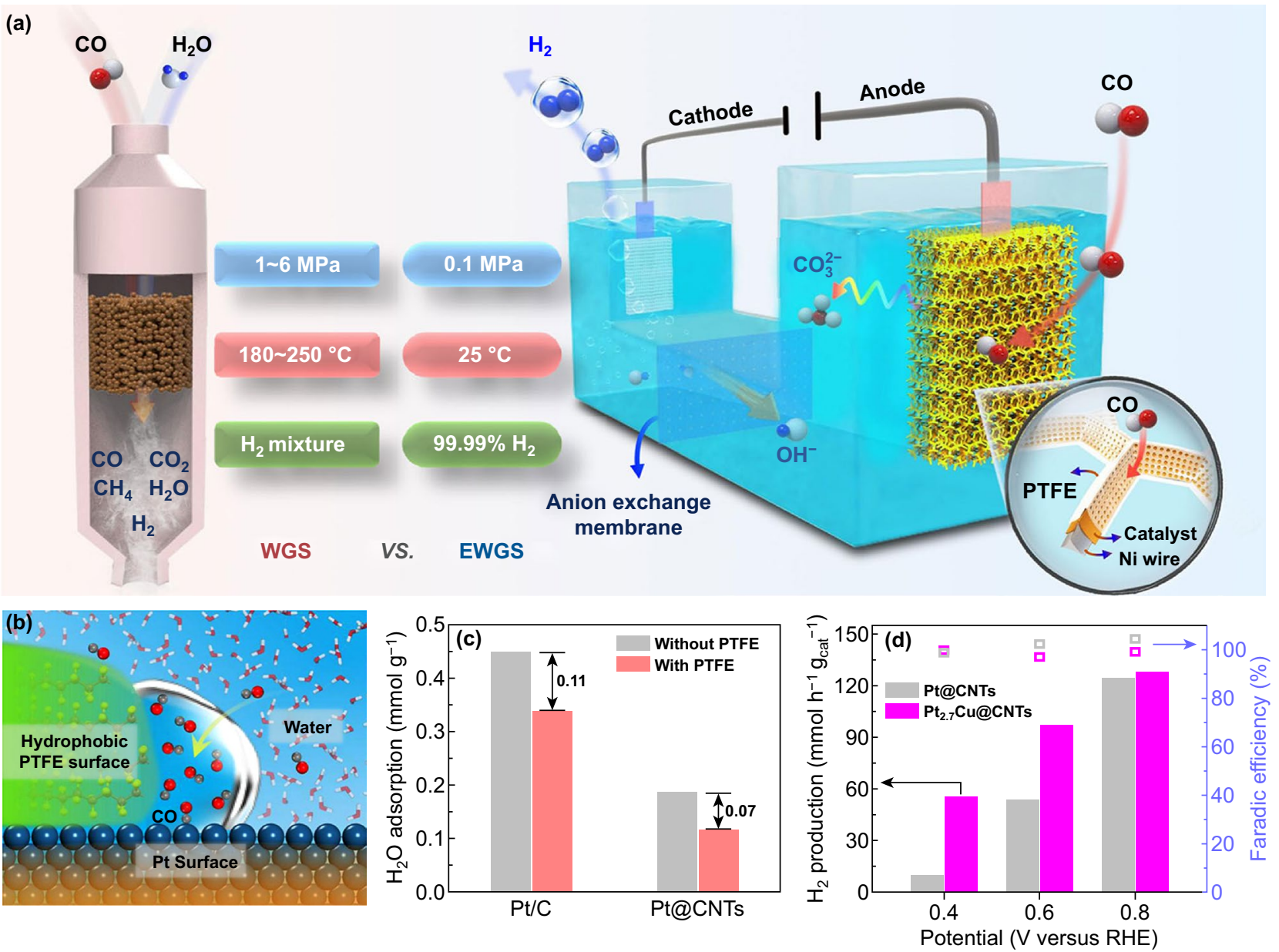

Fig. 16 a Schematic illustration of the EWGS process in comparison with the traditional WGS process, b schematic diagram of solid/liquid/gas interfaces on the PTFE-decorated Pt surface, $\mathbf{c}$ adsorption of $\mathrm{H}_{2} \mathrm{O}$ at $25{ }^{\circ} \mathrm{C}$ on Pt/C and Pt@CNTs with and without PTFE treatment detected by intelligent gravimetric analyzer, $\mathbf{d}$ the rate of $\mathrm{H}_{2}$ production and $\mathrm{FE}$ on the cathode at different potentials with the $\mathrm{Pt}_{2.7} \mathrm{Cu} @ \mathrm{CNTs}$ and $\mathrm{Pt} @ \mathrm{CNTs}$ as the anode catalysts. Reproduced with permission from Ref. [205]. Copyright 2019 Springer Nature

pyroelectric devices, and EWGS devices can efficiently utilize renewable energy for water splitting with lower or even no external power source. Therefore, the development of green energy system is significant for utilizing the renewable energy for water splitting.

Although many important developments have been made for green energy systems powered water splitting, this field also faces some challenges. Firstly, most non-noble metal bifunctional catalysts for water splitting show excellent performance only in the alkaline electrolytes, while rare low-cost catalysts for water splitting can work well in the acidic electrolytes. With the introduction of PEM in acidic electrolytes, the utilization of low-cost catalysts for water splitting is attractive. Therefore, the development of highly active non-noble metal catalysts for HER and OER in PEM water electrolyzer is the key thing that needs to be strengthened. Secondly, many developed low-cost catalysts for alkaline water splitting are unable to meet the requirements of high current density and long-term stability in industrial applications. As a consequence, the development of high stability, abundant active sites and large size of electrode for HER and OER is crucial for industrial applications. Thirdly, utilizing the photovoltaic device/TE devices/pyroelectric devices/TENG devices to convert solar energy/thermal energy/wind energy/water energy to electrical energy for delivering water splitting is a promising way to achieve renewable energy driven $\mathrm{H}_{2}$ production. However, the photovoltaic device/TE devices/pyroelectric devices/TENG 
devices in tandem with an electrolyzer will obviously increase the cost for $\mathrm{H}_{2}$ production. Therefore, improving the compatibility of devices and the integrity of systems by integrated the photovoltaic device/TE devices/pyroelectric devices/TENG devices with an electrolyzer into a single system will decrease the overall cost for $\mathrm{H}_{2}$ production in future practical application.

During the past few years, the different driven systems for water splitting have made great progress and many exciting achievements. With the incessant efforts that are being devoted to this field, water splitting driven by green energy systems will make a significant contribution to large-scale practical applications of clean energy systems in the near future. We hope this review will encourage more efforts into the development of novel green energy system for hydrogen energy production to realize the whole process with low cost, pollution-free and energy sustainability conversion in practical applications.

Acknowledgements This work was supported by Taishan Scholars Project Special Funds (tsqn201812083), Natural Science Foundation of Shandong Province (ZR2019YQ20, 2019JMRH0410) and the National Natural Science Foundation of China (51972147).

Open Access This article is licensed under a Creative Commons Attribution 4.0 International License, which permits use, sharing, adaptation, distribution and reproduction in any medium or format, as long as you give appropriate credit to the original author(s) and the source, provide a link to the Creative Commons licence, and indicate if changes were made. The images or other third party material in this article are included in the article's Creative Commons licence, unless indicated otherwise in a credit line to the material. If material is not included in the article's Creative Commons licence and your intended use is not permitted by statutory regulation or exceeds the permitted use, you will need to obtain permission directly from the copyright holder. To view a copy of this licence, visit http://creativecommons.org/licenses/by/4.0/.

\section{References}

1. E. Hu, Y. Feng, J. Nai, D. Zhao, Y. Hu, X.W. Lou, Construction of hierarchical Ni-Co-P hollow nanobricks with oriented nanosheets for efficient overall water splitting. Energy Environ. Sci. 11(4), 872-880 (2018). https://doi.org/10.1039/ C8EE00076J

2. F. Yu, H. Zhou, Y. Huang, J. Sun, F. Qin et al., High-performance bifunctional porous non-noble metal phosphide catalyst for overall water splitting. Nat. Commun. 9(1), 2551 (2018). https://doi.org/10.1038/s41467-018-04746-z
3. B. You, Y. Sun, Innovative strategies for electrocatalytic water splitting. Acc. Chem. Res. 51(7), 1571-1580 (2018). https://doi.org/10.1021/acs.accounts.8b00002

4. W. Wang, M. Xu, X. Xu, W. Zhou, Z. Shao, Perovskite oxide based electrodes for high-performance photoelectrochemical water splitting. Angew. Chem. Int. Ed. 59(1), 136-152 (2020). https://doi.org/10.1002/anie.201900292

5. K. Oka, O. Tsujimura, T. Suga, H. Nishide, B. WintherJensen, Light-assisted electrochemical water-splitting at very low bias voltage using metal-free polythiophene as photocathode at high $\mathrm{pH}$ in a full-cell setup. Energy Environ. Sci. 11(5), 1335-1342 (2018). https://doi.org/10.1039/C7EE0 3669H

6. S.Y. Tee, K.Y. Win, W.S. Teo, L.D. Koh, S. Liu, C.P. Teng, M.Y. Han, Recent progress in energy-driven water splitting. Adv. Sci. 4(5), 1600337 (2017). https://doi.org/10.1002/ advs. 201600337

7. S. Anantharaj, S.R. Ede, K. Karthick, S. Sam Sankar, K. Sangeetha, P.E. Karthik, S. Kundu, Precision and correctness in the evaluation of electrocatalytic water splitting: revisiting activity parameters with a critical assessment. Energy Environ. Sci. 11(4), 744-771 (2018). https://doi.org/10.1039/ C7EE03457A

8. J. Yu, G. Li, H. Liu, L. Zhao, A. Wang et al., Ru-Ru ${ }_{2} \mathrm{P} \Phi N P C$ and NPC@ $\mathrm{RuO}_{2}$ synthesized via environment-friendly and solid-phase phosphating process by saccharomycetes as N/P sources and carbon template for overall water splitting in acid electrolyte. Adv. Funct. Mater. 29(22), 1901154 (2019). https ://doi.org/10.1002/adfm.201901154

9. C. Guan, W. Xiao, H. Wu, X. Liu, W. Zang et al., Hollow Modoped CoP nanoarrays for efficient overall water splitting. Nano Energy 48, 73-80 (2018). https://doi.org/10.1016/j. nanoen.2018.03.034

10. H. Wu, X. Lu, G. Zheng, G.W. Ho, Topotactic engineering of ultrathin 2D nonlayered nickel selenides for full water electrolysis. Adv. Energy Mater. 8(14), 1702704 (2018). https:// doi.org/10.1002/aenm.201702704

11. S. Chu, A. Majumdar, Opportunities and challenges for a sustainable energy future. Nature 488(7411), 294-303 (2012). https://doi.org/10.1038/nature11475

12. X. Ren, H. Fan, C. Wang, J. Ma, H. Li, M. Zhang, S. Lei, W. Wang, Wind energy harvester based on coaxial rotatory freestanding triboelectric nanogenerators for self-powered water splitting. Nano Energy 50, 562-570 (2018). https:// doi.org/10.1016/j.nanoen.2018.06.002

13. I. Roger, M.A. Shipman, M.D. Symes, Earth-abundant catalysts for electrochemical and photoelectrochemical water splitting. Nat. Rev. Chem. 1(1), 0003 (2017). https://doi. org/10.1038/s41570-016-0003

14. Z. Wang, C. Li, K. Domen, Recent developments in heterogeneous photocatalysts for solar-driven overall water splitting. Chem. Soc. Rev. 48(7), 2109-2125 (2019). https://doi. org/10.1039/C8CS00542G

15. W. Yang, R.R. Prabhakar, J. Tan, S.D. Tilley, J. Moon, Strategies for enhancing the photocurrent, photovoltage, and stability of photoelectrodes for photoelectrochemical water 
splitting. Chem. Soc. Rev. 48(19), 4979-5015 (2019). https ://doi.org/10.1039/C8CS00997J

16. F. Niu, D. Wang, F. Li, Y. Liu, S. Shen, T.J. Meyer, Hybrid photoelectrochemical water splitting systems: from interface design to system assembly. Adv. Energy Mater. 10(11), 1900399 (2019). https://doi.org/10.1002/aenm.201900399

17. H. Zhou, F. Yu, Q. Zhu, J. Sun, F. Qin et al., Water splitting by electrolysis at high current densities under 1.6 volts. Energy Environ. Sci. 11(10), 2858-2864 (2018). https://doi. org/10.1039/C8EE00927A

18. G. Li, J. Yu, J. Jia, L. Yang, L. Zhao, W. Zhou, H. Liu, Cobalt-cobalt phosphide nanoparticles@nitrogen-phosphorus doped carbon/graphene derived from cobalt ions adsorbed saccharomycete yeasts as an efficient, stable, and large-current-density electrode for hydrogen evolution reactions. Adv. Funct. Mater. 28(40), 1801332 (2018). https://doi. org/10.1002/adfm.201801332

19. X. Li, J. Yu, J. Jia, A. Wang, L. Zhao, T. Xiong, H. Liu, W. Zhou, Confined distribution of platinum clusters on $\mathrm{MoO}_{2}$ hexagonal nanosheets with oxygen vacancies as a high-efficiency electrocatalyst for hydrogen evolution reaction. Nano Energy 62, 127-135 (2019). https://doi.org/10.1016/j.nanoe n.2019.05.013

20. J. Jia, T. Xiong, L. Zhao, F. Wang, H. Liu, R. Hu, J. Zhou, W. Zhou, S. Chen, Ultrathin n-doped $\mathrm{Mo}_{2} \mathrm{C}$ nanosheets with exposed active sites as efficient electrocatalyst for hydrogen evolution reactions. ACS Nano 11(12), 12509-12518 (2017). https://doi.org/10.1021/acsnano.7b06607

21. W. Zhou, J. Lu, K. Zhou, L. Yang, Y. Ke, Z. Tang, S. Chen, $\mathrm{CoSe}_{2}$ nanoparticles embedded defective carbon nanotubes derived from MOFs as efficient electrocatalyst for hydrogen evolution reaction. Nano Energy 28, 143-150 (2016). https ://doi.org/10.1016/j.nanoen.2016.08.040

22. L.P. Wen, X.Y. Shan, J. Liu, H.R. Mu, Y. Xiao et al., Engineered superhydrophilic/superaerophobic electrocatalysts composed of supported CoMoSx chalcogels for overall water splitting. Angew. Chem. Int. Ed. 59(4), 1659-1665 (2020). https://doi.org/10.1002/anie.201911617

23. N.N. Han, K.R. Yang, Z.Y. Lu, Y.J. Li, W.W. Xu et al., Nitrogen-doped tungsten carbide nanoarray as an efficient bifunctional electrocatalyst for water splitting in acid. Nat. Commun. 9, 924 (2018). https://doi.org/10.1038/s41467-01803429-z

24. Z.Y. Lu, W. Zhu, X.Y. Yu, H.C. Zhang, Y.J. Li et al., Ultrahigh hydrogen evolution performance of under-water "Superaerophobic" $\mathrm{MoS}_{2}$ nanostructured electrodes. Adv. Mater. 26(17), 2683-2687 (2014). https://doi.org/10.1002/ adma.201304759

25. W. Xu, Z. Lu, X. Sun, L. Jiang, X. Duan, Superwetting electrodes for gas-involving electrocatalysis. Acc. Chem. Res. 51, 1590-1598 (2018). https://doi.org/10.1021/acs.accou nts. 8 b00070

26. H.Y. Li, S.M. Chen, Y. Zhang, Q.H. Zhang, X.F. Jia et al., Systematic design of superaerophobic nanotubearray electrode comprised of transition-metal sulfides for overall water splitting. Nat. Commun. 9, 2452 (2018). https://doi. org/10.1038/s41467-018-04888-0

27. D. Jeon, J. Park, C. Shin, H. Kim, J.-W. Jang, D.W. Lee, J. Ryu, Superaerophobic hydrogels for enhanced electrochemical and photoelectrochemical hydrogen production. Sci. Adv. 6, eaaz3944 (2020). https://doi.org/10.1126/sciadv.aaz3944

28. L. Zeng, L. Yang, J. Lu, J. Jia, J. Yu, Y. Deng, M. Shao, W. Zhou, One-step synthesis of Fe-Ni hydroxide nanosheets derived from bimetallic foam for efficient electrocatalytic oxygen evolution and overall water splitting. Chin. Chem. Lett. 29(12), 1875-1878 (2018). https://doi.org/10.1016/j. cclet.2018.10.026

29. J.H. Lin, Y.T. Yan, C. Li, X.Q. Si, H.H. Wang et al., Bifunctional electrocatalysts based on Mo-doped NiCoP nanosheet arrays for overall water splitting. Nano-Micro Lett. 11, 55 (2019). https://doi.org/10.1007/s40820-019-0289-6

30. Y. Yan, B.Y. Xia, B. Zhao, X. Wang, A review on noblemetal-free bifunctional heterogeneous catalysts for overall electrochemical water splitting. J. Mater. Chem. A 4(45), 17587-17603 (2016). https://doi.org/10.1039/C6TA08075H

31. Y. Ha, L. Shi, Z. Chen, R. Wu, Phase-transited lysozymedriven formation of self-supported $\mathrm{Co}_{3} \mathrm{O}_{4} @ \mathrm{C}$ nanomeshes for overall water splitting. Adv. Sci. 6(11), 1900272 (2019). https://doi.org/10.1002/advs.201900272

32. K. Chi, X. Tian, Q. Wang, Z. Zhang, X. Zhang et al., Oxygen vacancies engineered $\mathrm{CoMoO}_{4}$ nanosheet arrays as efficient bifunctional electrocatalysts for overall water splitting. J. Catal. 381, 44-52 (2020). https://doi.org/10.1016/j. jcat.2019.10.025

33. Y. Zhang, J. Fu, H. Zhao, R. Jiang, F. Tian, R. Zhang, Tremella-like $\mathrm{Ni}_{3} \mathrm{~S}_{2} / \mathrm{MnS}$ with ultrathin nanosheets and abundant oxygen vacancies directly used for high speed overall water splitting. Appl. Catal. B 257, 117899 (2019). https:// doi.org/10.1016/j.apcatb.2019.117899

34. N. Yao, P. Li, Z. Zhou, R. Meng, G. Cheng, W. Luo, Nitrogen engineering on 3D dandelion-flower-like $\mathrm{CoS}_{2}$ for highperformance overall water splitting. Small 15(31), 1901993 (2019). https://doi.org/10.1002/smll.201901993

35. Q. Qin, L. Chen, T. Wei, X. Liu, $\mathrm{MoS}_{2} / \mathrm{NiS}$ yolk-shell microsphere-based electrodes for overall water splitting and asymmetric supercapacitor. Small 15(29), 1803639 (2019). https ://doi.org/10.1002/smll.201803639

36. Y. Yang, K. Zhang, H. Lin, X. Li, H.C. Chan, L. Yang, Q. Gao, $\mathrm{MoS}_{2}-\mathrm{Ni}_{3} \mathrm{~S}_{2}$ heteronanorods as efficient and stable bifunctional electrocatalysts for overall water splitting. ACS Catal. 7(4), 2357-2366 (2017). https://doi.org/10.1021/acsca tal.6b03192

37. L. Li, C. Sun, B. Shang, Q. Li, J. Lei, N. Li, F. Pan, Tailoring the facets of $\mathrm{Ni}_{3} \mathrm{~S}_{2}$ as a bifunctional electrocatalyst for highperformance overall water-splitting. J. Mater. Chem. A 7(30), 18003-18011 (2019). https://doi.org/10.1039/C9TA05578A

38. J. Lin, P. Wang, H. Wang, C. Li, X. Si et al., Defect-rich heterogeneous $\mathrm{MoS}_{2} / \mathrm{NiS}_{2}$ nanosheets electrocatalysts for efficient overall water splitting. Adv. Sci. 6(14), 1900246 (2019). https://doi.org/10.1002/advs.201900246 
39. Y. Deng, Z. Liu, A. Wang, D. Sun, Y. Chen et al., Oxygenincorporated MoX (X: S, Se or P) nanosheets via universal and controlled electrochemical anodic activation for enhanced hydrogen evolution activity. Nano Energy 62, 338347 (2019). https://doi.org/10.1016/j.nanoen.2019.05.036

40. T. Zhang, L. Hang, Y. Sun, D. Men, X. Li, L. Wen, X. Lyu, Y. Li, Hierarchical hetero- $\mathrm{Ni}_{3} \mathrm{Se}_{4} @ \mathrm{NiFe} \mathrm{LDH}$ micro/nanosheets as efficient bifunctional electrocatalysts with superior stability for overall water splitting. Nanoscale Horiz. 4(5), 11321138 (2019). https://doi.org/10.1039/C9NH00177H

41. H. Sun, J.-G. Li, L. Lv, Z. Li, X. Ao, C. Xu, X. Xue, G. Hong, C. Wang, Engineering hierarchical CoSe/NiFe layereddouble-hydroxide nanoarrays as high efficient bifunctional electrocatalyst for overall water splitting. J. Power Sources 425, 138-146 (2019). https://doi.org/10.1016/j.jpows our.2019.04.014

42. F. Ming, H. Liang, H. Shi, X. Xu, G. Mei, Z. Wang, MOFderived co-doped nickel selenide/C electrocatalysts supported on $\mathrm{Ni}$ foam for overall water splitting. J. Mater. Chem. A 4(39), 15148-15155 (2016). https://doi.org/10.1039/C6TA0 $6496 \mathrm{E}$

43. N. Li, Y. Zhang, M. Jia, X. Lv, X. Li et al., 1T/2H $\mathrm{MoSe}_{2}$-on-mxene heterostructure as bifunctional electrocatalyst for efficient overall water splitting. Electrochim. Acta 326, 134976 (2019). https://doi.org/10.1016/j.elect acta.2019.134976

44. J. Wang, W. Yang, J. Liu, $\mathrm{CoP}_{2}$ nanoparticles on reduced graphene oxide sheets as a super-efficient bifunctional electrocatalyst for full water splitting. J. Mater. Chem. A 4(13), 4686-4690 (2016). https://doi.org/10.1039/C6TA00596A

45. Y. Li, H. Zhang, M. Jiang, Q. Zhang, P. He, X. Sun, 3D self-supported $\mathrm{Fe}$-doped $\mathrm{Ni}_{2} \mathrm{P}$ nanosheet arrays as bifunctional catalysts for overall water splitting. Adv. Funct. Mater. 27(37), 1702513 (2017). https://doi.org/10.1002/adfm.20170 2513

46. H. Sun, Y. Min, W. Yang, Y. Lian, L. Lin et al., Morphological and electronic tuning of $\mathrm{Ni}_{2} \mathrm{P}$ through iron doping toward highly efficient water splitting. ACS Catal. 9(10), 8882-8892 (2019). https://doi.org/10.1021/acscatal.9b02264

47. B. Cao, Y. Cheng, M. Hu, P. Jing, Z. Ma, B. Liu, R. Gao, J. Zhang, Efficient and durable 3D self-supported nitrogendoped carbon-coupled nickel/cobalt phosphide electrodes: Stoichiometric ratio regulated phase- and morphologydependent overall water splitting performance. Adv. Funct. Mater. 29(44), 1906316 (2019). https://doi.org/10.1002/ adfm. 201906316

48. L. Zhang, X. Wang, A. Li, X. Zheng, L. Peng et al., Rational construction of macroporous $\mathrm{CoFeP}$ triangular plate arrays from bimetal-organic frameworks as high-performance overall water-splitting catalysts. J. Mater. Chem. A 7(29), 17529-17535 (2019). https://doi.org/10.1039/C9TA05282H

49. J. Lin, Y. Yan, C. Li, X. Si, H. Wang et al., Bifunctional electrocatalysts based on Mo-doped NiCoP nanosheet arrays for overall water splitting. Nano-Micro Lett. 11(1), 55 (2019). https://doi.org/10.1007/s40820-019-0289-6
50. Y. Wang, C. Xie, D. Liu, X. Huang, J. Huo, S. Wang, Nanoparticle-stacked porous nickel-iron nitride nanosheet: a highly efficient bifunctional electrocatalyst for overall water splitting. ACS Appl. Mater. Interfaces. 8(29), 18652-18657 (2016). https://doi.org/10.1021/acsami.6b05811

51. A. Wu, Y. Xie, H. Ma, C. Tian, Y. Gu et al., Integrating the active OER and HER components as the heterostructures for the efficient overall water splitting. Nano Energy 44, 353-363 (2018). https://doi.org/10.1016/j.nanoen.2017.11.045

52. Y. Hu, D. Huang, J. Zhang, Y. Huang, M.S.J.T. Balogun, Y. Tong, Dual doping induced interfacial engineering of $\mathrm{Fe}_{2} \mathrm{~N} /$ $\mathrm{Fe}_{3} \mathrm{~N}$ hybrids with favorable d-band towards efficient overall water splitting. ChemCatChem 11(24), 6051-6060 (2019). https://doi.org/10.1002/cctc.201901224

53. Z. Liu, H. Tan, D. Liu, X. Liu, J. Xin et al., Promotion of overall water splitting activity over a wide $\mathrm{pH}$ range by interfacial electrical effects of metallic NiCo-nitrides nanoparticle $/ \mathrm{NiCo}_{2} \mathrm{O}_{4}$ nanoflake/graphite fibers. Adv. Sci. 6(5), 1801829 (2019). https://doi.org/10.1002/advs.201801829

54. Z. Yuan, J. Li, M. Yang, Z. Fang, J. Jian, D. Yu, X. Chen, L. Dai, Ultrathin black phosphorus-on-nitrogen doped graphene for efficient overall water splitting: dual modulation roles of directional interfacial charge transfer. J. Am. Chem. Soc. 141(12), 4972-4979 (2019). https://doi.org/10.1021/ jacs.9b00154

55. C. Xing, Y. Xue, B. Huang, H. Yu, L. Hui et al., Fluorographdiyne: a metal-free catalyst for applications in water reduction and oxidation. Angew. Chem. Int. Ed. 131(39), 14035-14041 (2019). https://doi.org/10.1002/anie.201905729

56. C.W. Liang, P.C. Zou, A. Nairan, Y.Q. Zhang, J.X. Liu et al., Exceptional performance of hierarchical Ni-Fe oxyhydroxide@NiFe alloy nanowire array electrocatalysts for large current density water splitting. Energy Environ. Sci. 13, 86-95 (2020). https://doi.org/10.1039/c9ee02388g

57. I. Vincent, D. Bessarabov, Low cost hydrogen production by anion exchange membrane electrolysis: a review. Renew. Sustain. Energy Rev. 81, 1690-1704 (2018). https://doi. org/10.1016/j.rser.2017.05.258

58. H. Ju, S. Badwal, S. Giddey, A comprehensive review of carbon and hydrocarbon assisted water electrolysis for hydrogen production. Appl. Energy 231, 502-533 (2018). https://doi. org/10.1016/j.apenergy.2018.09.125

59. C. Panda, P.W. Menezes, M. Zheng, S. Orthmann, M. Driess, In situ formation of nanostructured core-shell $\mathrm{Cu}_{3} \mathrm{~N}-\mathrm{CuO}$ to promote alkaline water electrolysis. ACS Energy Lett. 4(3), 747-754 (2019). https://doi.org/10.1021/acsenergylett.9b000 91

60. J.M. Wei, M. Zhou, A.C. Long, Y.M. Xue, H.B. Liao, C. Wei, Z.J. Xu, Heterostructured electrocatalysts for hydrogen evolution reaction under alkaline conditions. Nano-Micro Lett. 10, 75 (2018). https://doi.org/10.1007/s40820-018-0229-x

61. T. Zhang, K. Yang, C. Wang, S. Li, Q. Zhang et al., Nanometric $\mathrm{Ni}_{5} \mathrm{P}_{4}$ clusters nested on $\mathrm{NiCo}_{2} \mathrm{O}_{4}$ for efficient hydrogen production via alkaline water electrolysis. Adv. Energy Mater. 8(29), 1801690 (2018). https://doi.org/10.1002/aenm.20180 1690 
62. K. Zhang, M.B. McDonald, I.E.A. Genina, P.T. Hammond, A highly conductive and mechanically robust $\mathrm{OH}^{-}$conducting membrane for alkaline water electrolysis. Chem. Mater. 30(18), 6420-6430 (2018). https://doi.org/10.1021/acs. chemmater.8b02709

63. D. Aili, M.R. Kraglund, J. Tavacoli, C. Chatzichristodoulou, J.O. Jensen, Polysulfone-polyvinylpyrrolidone blend membranes as electrolytes in alkaline water electrolysis. J. Membr. Sci. 598, 117674 (2020). https://doi.org/10.1016/j. memsci.2019.117674

64. P. Fortin, T. Khoza, X. Cao, S.Y. Martinsen, A. Oyarce Barnett, S. Holdcroft, High-performance alkaline water electrolysis using Aemion ${ }^{\mathrm{TM}}$ anion exchange membranes. J. Power Sources 451, 227814 (2020). https://doi.org/10.1016/j.jpows our.2020.227814

65. M. Carmo, D.L. Fritz, J. Mergel, D. Stolten, A comprehensive review on PEM water electrolysis. Int. J. Hydrogen Energy 38(12), 4901-4934 (2013). https://doi.org/10.1016/j.ijhyd ene.2013.01.151

66. W. Tong, M. Forster, F. Dionigi, S. Dresp, R.S. Erami, P. Strasser, A.J. Cowan, P. Farràs, Electrolysis of low-grade and saline surface water. Nat. Energy (2020). https://doi. org/10.1038/s41560-020-0550-8

67. A. Kovač, D. Marciuš, L. Budin, Solar hydrogen production via alkaline water electrolysis. Int. J. Hydrogen Energy 44(20), 9841-9848 (2019). https://doi.org/10.1016/j.ijhyd ene.2018.11.007

68. S. Marini, P. Salvi, P. Nelli, R. Pesenti, M. Villa, M. Berrettoni, G. Zangari, Y. Kiros, Advanced alkaline water electrolysis. Electrochim. Acta 82, 384-391 (2012). https://doi. org/10.1016/j.electacta.2012.05.011

69. S. Barwe, B. Mei, J. Masa, W. Schuhmann, E. Ventosa, Overcoming cathode poisoning from electrolyte impurities in alkaline electrolysis by means of self-healing electrocatalyst films. Nano Energy 53, 763-768 (2018). https://doi. org/10.1016/j.nanoen.2018.09.045

70. R. Phillips, A. Edwards, B. Rome, D.R. Jones, C.W. Dunnill, Minimising the ohmic resistance of an alkaline electrolysis cell through effective cell design. Int. J. Hydrogen Energy 42(38), 23986-23994 (2017). https://doi.org/10.1016/j.ijhyd ene.2017.07.184

71. A. Gabler, C.I. Müller, T. Rauscher, T. Gimpel, R. Hahn et al., Ultrashort-pulse laser structured titanium surfaces with sputter-coated platinum catalyst as hydrogen evolution electrodes for alkaline water electrolysis. Int. J. Hydrogen Energy 43(15), 7216-7226 (2018). https://doi.org/10.1016/j. ijhydene.2018.02.130

72. J. Zhang, C. Zhang, J. Sha, H. Fei, Y. Li, J.M. Tour, Efficient water-splitting electrodes based on laser-induced graphene. ACS Appl. Mater. Interfaces. 9(32), 26840-26847 (2017). https://doi.org/10.1021/acsami.7b06727

73. S.M.H. Hashemi, P. Karnakov, P. Hadikhani, E. Chinello, S. Litvinov, C. Moser, P. Koumoutsakos, D. Psaltis, A versatile and membrane-less electrochemical reactor for the electrolysis of water and brine. Energy Environ. Sci. 12(5), 1592-1604 (2019). https://doi.org/10.1039/C9EE00219G
74. J.C. Bui, J.T. Davis, D.V. Esposito, 3D-printed electrodes for membraneless water electrolysis. Sustain. Energy Fuels 4(1), 213-225 (2020). https://doi.org/10.1039/C9SE00710E

75. M.I. Gillespie, R.J. Kriek, Hydrogen production from a rectangular horizontal filter press divergent electrode-flowthrough (DEFT ${ }^{\mathrm{TM}}$ ) alkaline electrolysis stack. J. Power Sources 372, 252-259 (2017). https://doi.org/10.1016/j.jpows our.2017.10.080

76. M.I. Gillespie, R.J. Kriek, Scalable hydrogen production from a mono-circular filter press divergent electrode-flow-through alkaline electrolysis stack. J. Power Sources 397, 204-213 (2018). https://doi.org/10.1016/j.jpowsour.2018.07.026

77. A.G. Wallace, M.D. Symes, Decoupling strategies in electrochemical water splitting and beyond. Joule 2(8), 1390-1395 (2018). https://doi.org/10.1016/j.joule.2018.06.011

78. J. Wang, L. Ji, X. Teng, Y. Liu, L. Guo, Z. Chen, Decoupling half-reactions of electrolytic water splitting by integrating a polyaniline electrode. J. Mater. Chem. A 7(21), 13149-13153 (2019). https://doi.org/10.1039/C9TA03285A

79. X. Liu, J. Chi, B. Dong, Y. Sun, Recent progress in decoupled $\mathrm{H}_{2}$ and $\mathrm{O}_{2}$ production from electrolytic water splitting. ChemElectroChem 6(8), 2157-2166 (2019). https://doi. org/10.1002/celc.201801671

80. A. Landman, H. Dotan, G.E. Shter, M. Wullenkord, A. Houaijia, A. Maljusch, G.S. Grader, A. Rothschild, Photoelectrochemical water splitting in separate oxygen and hydrogen cells. Nat. Mater. 16(6), 646-651 (2017). https:// doi.org/10.1038/nmat4876

81. Y. Ma, X. Dong, Y. Wang, Y. Xia, Decoupling hydrogen and oxygen production in acidic water electrolysis using a polytriphenylamine-based battery electrode. Angew. Chem. Int. Ed. 57(11), 2904-2908 (2018). https://doi.org/10.1002/ anie. 201800436

82. Y. Ma, Z. Guo, X. Dong, Y. Wang, Y. Xia, Organic protonbuffer electrode to separate hydrogen and oxygen evolution in acid water electrolysis. Angew. Chem. Int. Ed. 58(14), 4622-4626 (2019). https://doi.org/10.1002/anie.201814625

83. H. Dotan, A. Landman, S.W. Sheehan, K.D. Malviya, G.E. Shter et al., Decoupled hydrogen and oxygen evolution by a two-step electrochemical-chemical cycle for efficient overall water splitting. Nat. Energy 4(9), 786-795 (2019). https://doi. org/10.1038/s41560-019-0462-7

84. W.T. Grubb, Ionic migration in ion-exchange membranes. J. Phys. Chem. 63(1), 55-58 (1959). https://doi.org/10.1021/ j150571a015

85. E.J. Park, C.B. Capuano, K.E. Ayers, C. Bae, Chemically durable polymer electrolytes for solid-state alkaline water electrolysis. J. Power Sources 375, 367-372 (2018). https:// doi.org/10.1016/j.jpowsour.2017.07.090

86. M. Zhu, Q. Shao, Y. Qian, X. Huang, Superior overall water splitting electrocatalysis in acidic conditions enabled by bimetallic Ir-Ag nanotubes. Nano Energy 56, 330-337 (2019). https://doi.org/10.1016/j.nanoen.2018.11.023

87. L. Fu, F. Yang, G. Cheng, W. Luo, Ultrathin Ir nanowires as high-performance electrocatalysts for efficient water splitting 
in acidic media. Nanoscale 10(4), 1892-1897 (2018). https:// doi.org/10.1039/C7NR09377B

88. C. Liu, M. Carmo, G. Bender, A. Everwand, T. Lickert et al., Performance enhancement of PEM electrolyzers through iridium-coated titanium porous transport layers. Electrochem. Commun. 97, 96-99 (2018). https://doi.org/10.1016/j.eleco m.2018.10.021

89. J.-W. Yu, G.-B. Jung, Y.-J. Su, C.-C. Yeh, M.-Y. Kan, C.-Y. Lee, C.-J. Lai, Proton exchange membrane water electrolysis system-membrane electrode assembly with additive. Int. J. Hydrogen Energy 44(30), 15721-15726 (2019). https://doi. org/10.1016/j.ijhydene.2018.11.192

90. A. Zinser, G. Papakonstantinou, K. Sundmacher, Analysis of mass transport processes in the anodic porous transport layer in PEM water electrolysers. Int. J. Hydrogen Energy 44(52), 28077-28087 (2019). https://doi.org/10.1016/j.ijhyd ene.2019.09.081

91. W. Xu, K. Scott, The effects of ionomer content on PEM water electrolyser membrane electrode assembly performance. Int. J. Hydrogen Energy 35(21), 12029-12037 (2010). https://doi.org/10.1016/j.ijhydene.2010.08.055

92. P. Millet, R. Ngameni, S.A. Grigoriev, V.N. Fateev, Scientific and engineering issues related to PEM technology: water electrolysers, fuel cells and unitized regenerative systems. Int. J. Hydrogen Energy 36(6), 4156-4163 (2011). https:// doi.org/10.1016/j.ijhydene.2010.06.106

93. J.E. Bennett, Electrodes for generation of hydrogen and oxygen from seawater. Int. J. Hydrogen Energy 5(4), 401-408 (1980). https://doi.org/10.1016/0360-3199(80)90021-X

94. Y. Kuang, M.J. Kenney, Y.T. Meng, W.-H. Hung, Y.J. Liuf et al., Solar-driven, highly sustained splitting of seawater into hydrogen and oxygen fuels. Proc. Natl. Acad. Sci. U.S.A. 116, 6624-6629 (2019). https://doi.org/10.1073/pnas.19005 56116

95. S. Trasatti, Electrocatalysis in the anodic evolution of oxygen and chlorine. Electrochim. Acta 29(11), 1503-1512 (1984). https://doi.org/10.1016/0013-4686(84)85004-5

96. F. Dionigi, T. Reier, Z. Pawolek, M. Gliech, P. Strasser, Design criteria, operating conditions, and nickel-iron hydroxide catalyst materials for selective seawater electrolysis. Chemsuschem 9(9), 962 (2016). https://doi.org/10.1002/ cssc. 201501581

97. F.J. Quan, G.M. Zhan, H. Shang, Y.H. Huang, F.L. Jia, L.Z. Zhang, Z.H. Ai, Highly efficient electrochemical conversion of $\mathrm{CO}_{2}$ and $\mathrm{NaCl}$ to $\mathrm{CO}$ and $\mathrm{NaClO}$. Green Chem. 21, 3256 (2019). https://doi.org/10.1039/c9gc01099h

98. X. Long, L. Gao, F. Li, Y. Hu, S. Wei, C. Wang, T. Wang, J. Jin, J. Ma, Bamboo shoots shaped $\mathrm{FeVO}_{4}$ passivated $\mathrm{ZnO}$ nanorods photoanode for improved charge separation/transfer process towards efficient solar water splitting. Appl. Catal. B 257, 117813 (2019). https://doi.org/10.1016/j.apcat b. 2019.117813

99. J. Li, X. Jin, R. Li, Y. Zhao, X. Wang, X. Liu, H. Jiao, Copper oxide nanowires for efficient photoelectrochemical water splitting. Appl. Catal. B Environ. 240, 1-8 (2019). https://doi. org/10.1016/j.apcatb.2018.08.070
100. L.G. Xia, J.H. Li, J. Bai, L.S. Li, S. Chen, B.X. Zhou, BiVO photoanode with exposed (040) facets for enhanced photoelectrochemical performance. Nano-Micro Lett. 10, 11 (2018). https://doi.org/10.1007/s40820-017-0163-3

101. A. Landman, R. Halabi, P. Dias, H. Dotan, A. Mehlmann et al., Decoupled photoelectrochemical water splitting system for centralized hydrogen production. Joule 4(2), 448-471 (2020). https://doi.org/10.1016/j.joule.2019.12.006

102. J.H. Kim, J.S. Lee, Elaborately modified $\mathrm{BiVO}_{4}$ photoanodes for solar water splitting. Adv. Mater. 31(20), 1806938 (2019). https://doi.org/10.1002/adma.201806938

103. E. Edwardes Moore, V. Andrei, S. Zacarias, I.A.C. Pereira, E. Reisner, Integration of a hydrogenase in a lead halide perovskite photoelectrode for tandem solar water splitting. ACS Energy Lett. 5(1), 232-237 (2020). https://doi.org/10.1021/ acsenergylett.9b02437

104. M. Chen, Y. Liu, C. Li, A. Li, X. Chang et al., Spatial control of cocatalysts and elimination of interfacial defects towards efficient and robust CIGS photocathodes for solar water splitting. Energy Environ. Sci. 11(8), 2025-2034 (2018). https:// doi.org/10.1039/C7EE03650G

105. H. Kobayashi, N. Sato, M. Orita, Y. Kuang, H. Kaneko, T. Minegishi, T. Yamada, K. Domen, Development of highly efficient $\mathrm{CuIn}_{0.5} \mathrm{Ga}_{0.5} \mathrm{Se}_{2}$-based photocathode and application to overall solar driven water splitting. Energy Environ. Sci. 11(10), 3003-3009 (2018). https://doi.org/10.1039/C8EE0 1783B

106. L. Pan, J.H. Kim, M.T. Mayer, M.-K. Son, A. Ummadisingu et al., Boosting the performance of $\mathrm{Cu}_{2} \mathrm{O}$ photocathodes for unassisted solar water splitting devices. Nat. Catal. 1(6), 412-420 (2018). https://doi.org/10.1038/s41929-018-0077-6

107. X. Li, M. Jia, Y. Lu, N. Li, Y.-Z. Zheng, X. Tao, M. Huang, $\mathrm{Co}(\mathrm{OH})_{2} / \mathrm{BiVO}_{4}$ photoanode in tandem with a carbon-based perovskite solar cell for solar-driven overall water splitting. Electrochim. Acta 330, 135183 (2020). https://doi. org/10.1016/j.electacta.2019.135183

108. D. Shao, L. Zheng, D. Feng, J. He, R. Zhang et al., $\mathrm{TiO}_{2}-$ P3HT:PCBM photoelectrochemical tandem cells for solardriven overall water splitting. J. Mater. Chem. A 6(9), 40324039 (2018). https://doi.org/10.1039/C7TA09367E

109. M. Huang, W. Lei, M. Wang, S. Zhao, C. Li, M. Wang, H. Zhu, Large area high-performance bismuth vanadate photoanode for efficient solar water splitting. J. Mater. Chem. A 8(7), 3845-3850 (2020). https://doi.org/10.1039/C9TA1 $3715 \mathrm{G}$

110. P. Varadhan, H.-C. Fu, Y.-C. Kao, R.-H. Horng, J.-H. He, An efficient and stable photoelectrochemical system with 9\% solar-to-hydrogen conversion efficiency via InGaP/GaAs double junction. Nat. Commun. 10(1), 5282 (2019). https:// doi.org/10.1038/s41467-019-12977-x

111. V. Andrei, R.L.Z. Hoye, M. Crespo-Quesada, M. Bajada, S. Ahmad, M. De Volder, R. Friend, E. Reisner, Scalable triple cation mixed halide perovskite- $\mathrm{BiVO}_{4}$ tandems for bias-free water splitting. Adv. Energy Mater. 8(25), 1801403 (2018). https://doi.org/10.1002/aenm.201801403 
112. Y. Chen, X. Feng, Y. Liu, X. Guan, C. Burda, L. Guo, Metal oxide-based tandem cells for self-biased photoelectrochemical water splitting. ACS Energy Lett. 5(3), 844-866 (2020). https://doi.org/10.1021/acsenergylett.9b02620

113. X. Wang, W. Gao, Z. Zhao, L. Zhao, J.P. Claverie et al., Efficient photo-electrochemical water splitting based on hematite nanorods doped with phosphorus. Appl. Catal. B 248, 388393 (2019). https://doi.org/10.1016/j.apcatb.2019.02.048

114. G.D. Sabba, M.H. Kumar, L.H. Wong, J. Barber, M. Grätzel, N. Mathews, Perovskite-hematite tandem cells for efficient overall solar driven water splitting. Nano Lett. 15(6), 38333839 (2015). https://doi.org/10.1021/acs.nanolett.5b00616

115. J.H. Kim, Y. Jo, J.H. Kim, J.W. Jang, H.J. Kang et al., Wireless solar water splitting device with robust cobalt-catalyzed, dual-doped $\mathrm{BiVO}_{4}$ photoanode and perovskite solar cell in tandem: a dual absorber artificial leaf. ACS Nano 9(12), 11820-11829 (2015). https://doi.org/10.1021/acsnano.5b038 59

116. J. Luo, Z. Li, S. Nishiwaki, M. Schreier, M.T. Mayer et al., Targeting ideal dual-absorber tandem water splitting using perovskite photovoltaics and $\mathrm{CuIn}_{\mathrm{x}} \mathrm{Ga}_{1-\mathrm{x}} \mathrm{Se}_{2}$ photocathodes. Adv. Energy Mater. 5(24), 1501520 (2015). https://doi. org/10.1002/aenm.201501520

117. Y. Qiu, W. Liu, W. Chen, W. Chen, G. Zhou et al., Efficient solar-driven water splitting by nanocone $\mathrm{BiVO}_{4}$-perovskite tandem cells. Sci. Adv. 2(6), e1501764 (2016). https://doi. org/10.1126/sciadv.1501764

118. K.P. Sokol, W.E. Robinson, J. Warnan, N. Kornienko, M.M. Nowaczyk, A. Ruff, J.Z. Zhang, E. Reisner, Bias-free photoelectrochemical water splitting with photosystem II on a dye-sensitized photoanode wired to hydrogenase. Nat. Energy 3(11), 944-951 (2018). https://doi.org/10.1038/s4156 0-018-0232-y

119. J. Brillet, J.-H. Yum, M. Cornuz, T. Hisatomi, R. Solarska, J. Augustynski, M. Graetzel, K. Sivula, Highly efficient water splitting by a dual-absorber tandem cell. Nat. Photonics 6(12), 824-828 (2012). https://doi.org/10.1038/nphot on. 2012.265

120. X. Shi, K. Zhang, K. Shin, M. Ma, J. Kwon et al., Unassisted photoelectrochemical water splitting beyond $5.7 \%$ solar-tohydrogen conversion efficiency by a wireless monolithic photoanode/dye-sensitised solar cell tandem device. Nano Energy 13, 182-191 (2015). https://doi.org/10.1016/j.nanoe n.2015.02.018

121. V. González-Pedro, I. Zarazua, E.M. Barea, F. Fabregat-Santiago, E. de la Rosa, I. Mora-Seró, S. Giménez, Panchromatic solar-to- $\mathrm{H}_{2}$ conversion by a hybrid quantum dots-dye dual absorber tandem device. J. Phys. Chem. C 118(2), 891-895 (2014). https://doi.org/10.1021/jp4109893

122. X. Zhou, J. Zhou, G. Huang, R. Fan, S. Ju, Z. Mi, M. Shen, A bifunctional and stable $\mathrm{Ni}-\mathrm{Co}-\mathrm{S} / \mathrm{Ni}-\mathrm{Co}-\mathrm{P}$ bistratal electrocatalyst for $10.8 \%$-efficient overall solar water splitting. J. Mater. Chem. A 6(41), 20297-20303 (2018). https://doi. org/10.1039/C8TA07197G

123. L. Ma, W. Zhang, P. Zhao, J. Liang, Y. Hu et al., Highly efficient overall water splitting driven by all-inorganic perovskite solar cells and promoted by bifunctional bimetallic phosphide nanowire arrays. J. Mater. Chem. A 6(41), 20076-20082 (2018). https://doi.org/10.1039/C8TA08116F

124. L. Yao, A. Rahmanudin, N. Guijarro, K. Sivula, Organic semiconductor based devices for solar water splitting. Adv. Energy Mater. 8(32), 1802585 (2018). https://doi. org/10.1002/aenm.201802585

125. J. Yuan, Y. Zhang, L. Zhou, G. Zhang, H.-L. Yip et al., Single-junction organic solar cell with over $15 \%$ efficiency using fused-ring acceptor with electron-deficient core. Joule 3(4), 1140-1151 (2019). https://doi.org/10.1016/j.joule .2019 .01 .004

126. J. Jung, J. Lee, Thermovoltage-driven solar hydrogen for commercialized water splitting. SPIE (2015). https://doi. org/10.1117/2.1201512.006219

127. Y. Xin, X. Kan, L.-Y. Gan, Z. Zhang, Heterogeneous bimetallic phosphide/sulfide nanocomposite for efficient solarenergy-driven overall water splitting. ACS Nano 11(10), 10303-10312 (2017). https://doi.org/10.1021/acsnano.7b050 20

128. H. Song, S. Oh, H. Yoon, K.-H. Kim, S. Ryu, J. Oh, Bifunctional $\mathrm{NiFe}$ inverse opal electrocatalysts with heterojunction Si solar cells for $9.54 \%$-efficient unassisted solar water splitting. Nano Energy 42, 1-7 (2017). https://doi.org/10.1016/j. nanoen.2017.10.028

129. B. Koo, D. Kim, P. Boonmongkolras, S.R. Pae, S. Byun et al., Unassisted water splitting exceeding $9 \%$ solar-to-hydrogen conversion efficiency by $\mathrm{Cu}(\mathrm{In}, \mathrm{Ga})(\mathrm{S}, \mathrm{Se})_{2}$ photocathode with modified surface band structure and halide perovskite solar cell. ACS Appl. Energy Mater. 3(3), 2296-2303 (2020). https://doi.org/10.1021/acsaem.9b02387

130. B. Kim, G.S. Park, Y.J. Hwang, D.H. Won, W. Kim, D.K. Lee, B.K. Min, $\mathrm{Cu}(\mathrm{In}, \mathrm{Ga})(\mathrm{S}, \mathrm{Se})_{2}$ photocathodes with a grown-in $\mathrm{Cu}_{\mathrm{x}} \mathrm{S}$ catalyst for solar water splitting. ACS Energy Lett. 4(12), 2937-2944 (2019). https://doi.org/10.1021/acsen ergylett.9b01816

131. N. Gaillard, D. Prasher, M. Chong, A. Deangelis, K. Horsley et al., Wide-bandgap $\mathrm{Cu}(\mathrm{In}, \mathrm{Ga}) \mathrm{S}_{2}$ photocathodes integrated on transparent conductive $\mathrm{F}: \mathrm{SnO}_{2}$ substrates for chalcopyrite-based water splitting tandem devices. ACS Appl. Energy Mater. 2(8), 5515-5524 (2019). https://doi. org/10.1021/acsaem.9b00690

132. T.J. Jacobsson, V. Fjällström, M. Sahlberg, M. Edoff, T. Edvinsson, A monolithic device for solar water splitting based on series interconnected thin film absorbers reaching over 10\% solar-to-hydrogen efficiency. Energy Environ. Sci. 6(12), 3676-3683 (2013). https://doi.org/10.1039/C3EE4 2519C

133. T.J. Jacobsson, C. Platzer-Björkman, M. Edoff, T. Edvinsson, $\mathrm{CuIn}_{\mathrm{x}} \mathrm{Ga}_{1-\mathrm{x}} \mathrm{Se}_{2}$ as an efficient photocathode for solar hydrogen generation. Int. J. Hydrogen Energy 38(35), 15027-15035 (2013). https://doi.org/10.1016/j.ijhyd ene.2013.09.094

134. A.F. Palmstrom, G.E. Eperon, T. Leijtens, R. Prasanna, S.N. Habisreutinger et al., Enabling flexible all-perovskite 
tandem solar cells. Joule 3(9), 2193-2204 (2019). https:// doi.org/10.1016/j.joule.2019.05.009

135. C. Wang, Z. Song, C. Li, D. Zhao, Y. Yan, Low-bandgap mixed tin-lead perovskites and their applications in allperovskite tandem solar cells. Adv. Funct. Mater. 29(47), 1808801 (2019). https://doi.org/10.1002/adfm.201808801

136. Z. Yang, Z. Yu, H. Wei, X. Xiao, Z. Ni et al., Enhancing electron diffusion length in narrow-bandgap perovskites for efficient monolithic perovskite tandem solar cells. Nat. Commun. 10(1), 4498 (2019). https://doi.org/10.1038/ s41467-019-12513-x

137. D. Zhao, C. Chen, C. Wang, M.M. Junda, Z. Song et al., Efficient two-terminal all-perovskite tandem solar cells enabled by high-quality low-bandgap absorber layers. Nat. Energy 3(12), 1093-1100 (2018). https://doi.org/10.1038/ s41560-018-0278-x

138. R. Lin, H. Lei, D. Ruan, K. Jiang, X. Yu, Z. Wang, W. Mai, H. Yan, Solar-powered overall water splitting system combing metal-organic frameworks derived bimetallic nanohybrids based electrocatalysts and one organic solar cell. Nano Energy 56, 82-91 (2019). https://doi.org/10.1016/j. nanoen.2018.10.058

139. X. Liu, Y. Wang, X. Cui, M. Zhang, B. Wang et al., Enabling highly efficient photocatalytic hydrogen generation and organics degradation via a perovskite solar cell-assisted semiconducting nanocomposite photoanode. J. Mater. Chem. A 7(1), 165-171 (2019). https://doi.org/10.1039/C8TA08998A

140. J. Luo, J.-H. Im, M.T. Mayer, M. Schreier, M.K. Nazeeruddin et al., Water photolysis at $12.3 \%$ efficiency via perovskite photovoltaics and earth-abundant catalysts. Science 345(6204), 1593 (2014). https://doi.org/10.1126/scien ce. 1258307

141. A. Kumar, D.K. Chaudhary, S. Parvin, S. Bhattacharyya, High performance duckweed-derived carbon support to anchor NiFe electrocatalysts for efficient solar energy driven water splitting. J. Mater. Chem. A 6(39), 1894818959 (2018). https://doi.org/10.1039/C8TA06946H

142. R. Merienne, J. Lynn, E. McSweeney, S.M. O’Shaughnessy, Thermal cycling of thermoelectric generators: the effect of heating rate. Appl. Energy 237, 671-681 (2019). https://doi. org/10.1016/j.apenergy.2019.01.041

143. Y. Liu, N. Sun, J. Liu, Z. Wen, X. Sun, S.-T. Lee, B. Sun, Integrating a silicon solar cell with a triboelectric nanogenerator via a mutual electrode for harvesting energy from sunlight and raindrops. ACS Nano 12(3), 2893-2899 (2018). https:// doi.org/10.1021/acsnano.8b00416

144. L. Xu, Y. Xiong, A. Mei, Y. Hu, Y. Rong, Y. Zhou, B. Hu, H. Han, Efficient perovskite photovoltaic-thermoelectric hybrid device. Adv. Energy Mater. 8(13), 1702937 (2018). https:// doi.org/10.1002/aenm.201702937

145. G. Li, S. Shittu, T.M.O. Diallo, M. Yu, X. Zhao, J. Ji, A review of solar photovoltaic-thermoelectric hybrid system for electricity generation. Energy 158, 41-58 (2018). https:// doi.org/10.1016/j.energy.2018.06.021

146. Z. Yang, W. Li, X. Chen, S. Su, G. Lin, J. Chen, Maximum efficiency and parametric optimum selection of a concentrated solar spectrum splitting photovoltaic cell-thermoelectric generator system. Energy Convers. Manag. 174, 65-71 (2018). https://doi.org/10.1016/j.enconman.2018.08.038

147. G. Li, S. Shittu, X. Ma, X. Zhao, Comparative analysis of thermoelectric elements optimum geometry between photovoltaic-thermoelectric and solar thermoelectric. Energy 171, 599-610 (2019). https://doi.org/10.1016/j.energ y.2019.01.057

148. D. Zhang, Y. Wang, Y. Yang, Design, performance, and application of thermoelectric nanogenerators. Small 15(32), 1805241 (2019). https://doi.org/10.1002/smll.201805241

149. J. Zhang, H. Zhai, Z. Wu, Y. Wang, H. Xie, M. Zhang, Enhanced performance of photovoltaic-thermoelectric coupling devices with thermal interface materials. Energy Rep. 6, 116-122 (2020). https://doi.org/10.1016/j.egyr.2019.12.001

150. A. Majumdar, Thermoelectricity in semiconductor nanostructures. Science 303(5659), 777 (2004). https://doi. org/10.1126/science.1093164

151. L. Yang, Z.G. Chen, M.S. Dargusch, J. Zou, High performance thermoelectric materials: progress and their applications. Adv. Energy Mater. 8(6), 1701797 (2017). https://doi. org/10.1002/aenm.201701797

152. J.L. Blackburn, A.J. Ferguson, C. Cho, J.C. Grunlan, Carbonnanotube-based thermoelectric materials and devices. Adv. Mater. 30(11), 1704386 (2018). https://doi.org/10.1002/ adma.201704386

153. S. Sun, W. Wang, D. Jiang, L. Zhang, J. Zhou, Infrared light induced photoelectrocatalytic application via graphene oxide coated thermoelectric device. Appl. Catal. B 158-159, 136139 (2014). https://doi.org/10.1016/j.apcatb.2014.04.009

154. S.A. Shankaregowda, R.F.S.M. Ahmed, C.B. Nanjegowda, J. Wang, S. Guan et al., Single-electrode triboelectric nanogenerator based on economical graphite coated paper for harvesting waste environmental energy. Nano Energy 66, 104141 (2019). https://doi.org/10.1016/j.nanoen.2019.104141

155. X. Huang, W. Zhang, G. Guan, G. Song, R. Zou, J. Hu, Design and functionalization of the NIR-responsive photothermal semiconductor nanomaterials for cancer theranostics. Acc. Chem. Res. 50(10), 2529-2538 (2017). https://doi. org/10.1021/acs.accounts.7b00294

156. X. Zhang, W. Gao, X. Su, F. Wang, B. Liu, J.-J. Wang, H. Liu, Y. Sang, Conversion of solar power to chemical energy based on carbon nanoparticle modified photo-thermoelectric generator and electrochemical water splitting system. Nano Energy 48, 481-488 (2018). https://doi.org/10.1016/j.nanoe n.2018.03.055

157. L. Zhao, Z. Yang, Q. Cao, L. Yang, X. Zhang et al., An earthabundant and multifunctional Ni nanosheets array as electrocatalysts and heat absorption layer integrated thermoelectric device for overall water splitting. Nano Energy 56, 563-570 (2019). https://doi.org/10.1016/j.nanoen.2018.11.035

158. L. Huang, J. Chen, Z. Yu, D. Tang, Self-powered temperature sensor with seebeck effect transduction for photothermal-thermoelectric coupled immunoassay. Anal. Chem. 92(3), 2809-2814 (2020). https://doi.org/10.1021/acs.analc hem. $9 \mathrm{~b} 05218$ 
159. V. Andrei, K. Bethke, K. Rademann, Thermoelectricity in the context of renewable energy sources: joining forces instead of competing. Energy Environ. Sci. 9(5), 1528-1532 (2016). https://doi.org/10.1039/C6EE00247A

160. J.-Y. Jung, D.W. Kim, D.-H. Kim, T.J. Park, R.B. Wehrspohn, J.-H. Lee, Seebeck-voltage-triggered self-biased photoelectrochemical water splitting using $\mathrm{HfO}_{\mathrm{x}} / \mathrm{SiO}_{\mathrm{x}}$ bi-layer protected Si photocathodes. Sci. Rep. 9(1), 9132 (2019). https:// doi.org/10.1038/s41598-019-45672-4

161. N. Getoff, Basic problems of photochemical and photoelectrochemical hydrogen production from water. Int. J. Hydrogen Energy 9(12), 997-1004 (1984). https://doi. org/10.1016/0360-3199(84)90171-X

162. S.-M. Shin, J.-Y. Jung, M.-J. Park, J.-W. Song, J.-H. Lee, Catalyst-free hydrogen evolution of Si photocathode by thermovoltage-driven solar water splitting. J. Power Sources 279, 151-156 (2015). https://doi.org/10.1016/j.jpows our.2015.01.020

163. N. Wang, L. Han, H. He, N.-H. Park, K. Koumoto, A novel high-performance photovoltaic-thermoelectric hybrid device. Energy Environ. Sci. 4(9), 3676-3679 (2011). https://doi. org/10.1039/C1EE01646F

164. Y. Yang, H. Zhang, Z.-H. Lin, Y. Liu, J. Chen et al., A hybrid energy cell for self-powered water splitting. Energy Environ. Sci. 6(8), 2429-2434 (2013). https://doi.org/10.1039/C3EE4 $1485 \mathrm{~J}$

165. L. Jin, B. Zhang, L. Zhang, W. Yang, Nanogenerator as new energy technology for self-powered intelligent transportation system. Nano Energy 66, 104086 (2019). https://doi. org/10.1016/j.nanoen.2019.104086

166. X. Xia, H. Wang, P. Basset, Y. Zhu, Y. Zi, Inductor-free output multiplier for power promotion and management of triboelectric nanogenerators toward self-powered systems. ACS Appl. Mater. Interfaces 12(5), 5892-5900 (2020). https://doi. org/10.1021/acsami.9b20060

167. J. Han, X. Meng, L. Lu, Z.L. Wang, C. Sun, Triboelectric nanogenerators powered electrodepositing tri-functional electrocatalysts for water splitting and rechargeable zinc-air battery: a case of Pt nanoclusters on NiFe-LDH nanosheets. Nano Energy 72, 104669 (2020). https://doi. org/10.1016/j.nanoen.2020.104669

168. A. Wei, X. Xie, Z. Wen, H. Zheng, H. Lan et al., Triboelectric nanogenerator driven self-powered photoelectrochemical water splitting based on hematite photoanodes. ACS Nano 12(8), 8625-8632 (2018). https://doi.org/10.1021/ acsnano.8b04363

169. S. Shittu, G. Li, Y.G. Akhlaghi, X. Ma, X. Zhao, E. Ayodele, Advancements in thermoelectric generators for enhanced hybrid photovoltaic system performance. Renew. Sustain. Energy Rev. 109, 24-54 (2019). https:// doi.org/10.1016/j.rser.2019.04.023

170. X. Meng, J. Han, L. Lu, G. Qiu, Z.L. Wang, C. Sun, $\mathrm{Fe}^{2+}$-doped layered double $(\mathrm{Ni}, \mathrm{Fe})$ hydroxides as efficient electrocatalysts for water splitting and self-powered electrochemical systems. Small 15(41), 1902551 (2019). https ://doi.org/10.1002/smll.201902551
171. P. Cheng, Y. Liu, Z. Wen, H. Shao, A. Wei et al., Atmospheric pressure difference driven triboelectric nanogenerator for efficiently harvesting ocean wave energy. Nano Energy 54, 156-162 (2018). https://doi.org/10.1016/j.nanoe n.2018.10.007

172. W. Tang, Y. Han, C.B. Han, C.Z. Gao, X. Cao, Z.L. Wang, Self-powered water splitting using flowing kinetic energy. Adv. Mater. 27(2), 272-276 (2015). https://doi.org/10.1002/ adma.201404071

173. T. Li, Y. Xu, F. Xing, X. Cao, J. Bian, N. Wang, Z.L. Wang, Boosting photoelectrochemical water splitting by TENGcharged Li-ion battery. Adv. Energy Mater. 7(15), 1700124 (2017). https://doi.org/10.1002/aenm.201700124

174. H. Askari, A. Khajepour, M.B. Khamesee, Z.L. Wang, Embedded self-powered sensing systems for smart vehicles and intelligent transportation. Nano Energy 66, 104103 (2019). https://doi.org/10.1016/j.nanoen.2019.104103

175. W. Tang, B.D. Chen, Z.L. Wang, Recent progress in power generation from water/liquid droplet interaction with solid surfaces. Adv. Funct. Mater. 29(41), 1901069 (2019). https ://doi.org/10.1002/adfm.201901069

176. H. Yang, M. Deng, Q. Zeng, X. Zhang, J. Hu et al., Polydirectional microvibration energy collection for self-powered multifunctional systems based on hybridized nanogenerators. ACS Nano 14(3), 3328-3336 (2020). https://doi.org/10.1021/ acsnano.9b08998

177. J.-W. Lee, W. Hwang, Theoretical study of micro/nano roughness effect on water-solid triboelectrification with experimental approach. Nano Energy 52, 315-322 (2018). https://doi. org/10.1016/j.nanoen.2018.08.008

178. J. Xiong, H. Luo, D. Gao, X. Zhou, P. Cui, G. Thangavel, K. Parida, P.S. Lee, Self-restoring, waterproof, tunable microstructural shape memory triboelectric nanogenerator for selfpowered water temperature sensor. Nano Energy 61, 584-593 (2019). https://doi.org/10.1016/j.nanoen.2019.04.089

179. Y. Feng, L. Zhang, Y. Zheng, D. Wang, F. Zhou, W. Liu, Leaves based triboelectric nanogenerator (TENG) and TENG tree for wind energy harvesting. Nano Energy 55, 260-268 (2019). https://doi.org/10.1016/j.nanoe n. 2018.10 .075

180. H. Lin, M. He, Q. Jing, W. Yang, S. Wang et al., Angleshaped triboelectric nanogenerator for harvesting environmental wind energy. Nano Energy 56, 269-276 (2019). https ://doi.org/10.1016/j.nanoen.2018.11.037

181. K. Han, J. Luo, Y. Feng, Q. Lai, Y. Bai, W. Tang, Z.L. Wang, Wind-driven radial-engine-shaped triboelectric nanogenerators for self-powered absorption and degradation of $\mathrm{NO}_{\mathrm{x}}$. ACS Nano 14(3), 2751-2759 (2020). https://doi.org/10.1021/ acsnano.9b08496

182. M.T. Rahman, M. Salauddin, P. Maharjan, M.S. Rasel, H. Cho, J.Y. Park, Natural wind-driven ultra-compact and highly efficient hybridized nanogenerator for self-sustained wireless environmental monitoring system. Nano Energy 57, 256-268 (2019). https://doi.org/10.1016/j.nanoen.2018.12.052

183. X. Zhao, B. Chen, G. Wei, J.M. Wu, W. Han, Y. Yang, Polyimide/graphene nanocomposite foam-based wind-driven 
triboelectric nanogenerator for self-powered pressure sensor. Adv. Mater. Technol. 4(5), 1800723 (2019). https://doi. org/10.1002/admt.201800723

184. M. Xie, S. Dunn, E.L. Boulbar, C.R. Bowen, Pyroelectric energy harvesting for water splitting. Int. J. Hydrogen Energy 42(37), 23437-23445 (2017). https://doi.org/10.1016/j.ijhyd ene.2017.02.086

185. Y. Zhang, S. Kumar, F. Marken, M. Krasny, E. Roake et al., Pyro-electrolytic water splitting for hydrogen generation. Nano Energy 58, 183-191 (2019). https://doi.org/10.1016/j. nanoen.2019.01.030

186. J. Schlechtweg, S. Raufeisen, M. Stelter, P. Braeutigam, A novel model for pyro-electro-catalytic hydrogen production in pure water. Phys. Chem. Chem. Phys. 21(41), 23009-23016 (2019). https://doi.org/10.1039/c9cp02510c

187. Y. Zhang, P.T.T. Phuong, E. Roake, H. Khanbareh, Y. Wang, S. Dunn, C. Bowen, Thermal energy harvesting using pyroelectric-electrochemical coupling in ferroelectric materials. Joule 4(2), 301-309 (2020). https://doi.org/10.1016/j.joule .2019 .12 .019

188. T. Ding, L. Zhu, X.-Q. Wang, K.H. Chan, X. Lu, Y. Cheng, G.W. Ho, Hybrid photothermal pyroelectric and thermogalvanic generator for multisituation low grade heat harvesting. Adv. Energy Mater. 8(33), 1802397 (2018). https://doi. org/10.1002/aenm.201802397

189. S. Pandya, J. Wilbur, J. Kim, R. Gao, A. Dasgupta, C. Dames, L.W. Martin, Pyroelectric energy conversion with large energy and power density in relaxor ferroelectric thin films. Nat. Mater. 17(5), 432-438 (2018). https://doi.org/10.1038/ s41563-018-0059-8

190. J. Harada, Y. Kawamura, Y. Takahashi, Y. Uemura, T. Hasegawa, H. Taniguchi, K. Maruyama, Plastic/ferroelectric crystals with easily switchable polarization: low-voltage operation, unprecedentedly high pyroelectric performance, and large piezoelectric effect in polycrystalline forms. J. Am. Chem. Soc. 141(23), 9349-9357 (2019). https://doi. org/10.1021/jacs.9b03369

191. K. Zhang, Y. Wang, Z.L. Wang, Y. Yang, Standard and figure-of-merit for quantifying the performance of pyroelectric nanogenerators. Nano Energy 55, 534-540 (2019). https:// doi.org/10.1016/j.nanoen.2018.11.020

192. S. Pandya, G.A. Velarde, R. Gao, A.S. Everhardt, J.D. Wilbur et al., Understanding the role of ferroelastic domains on the pyroelectric and electrocaloric effects in ferroelectric thin films. Adv. Mater. 31(5), 1803312 (2019). https://doi. org/10.1002/adma.201803312

193. L. Kuai, S. Liu, S. Cao, Y. Ren, E. Kan et al., Atomically dispersed Pt/metal oxide mesoporous catalysts from synchronous pyrolysis-deposition route for water-gas shift reaction. Chem. Mater. 30(16), 5534-5538 (2018). https://doi. org/10.1021/acs.chemmater.8b02144

194. L. Pastor-Pérez, V. Belda-Alcázar, C. Marini, M.M. PastorBlas, A. Sepúlveda-Escribano, E.V. Ramos-Fernandez, Effect of cold ar plasma treatment on the catalytic performance of $\mathrm{Pt} / \mathrm{CeO}_{2}$ in water-gas shift reaction (WGS). Appl.
Catal. B 225, 121-127 (2018). https://doi.org/10.1016/j.apcat b.2017.11.065

195. L. Zhao, Y. Qi, L. Song, S. Ning, S. Ouyang, H. Xu, J. Ye, Solar-driven water-gas shift reaction over $\mathrm{CuO}_{\mathrm{x}} / \mathrm{Al}_{2} \mathrm{O}_{3}$ with $1.1 \%$ of light-to-energy storage. Angew. Chem. Int. Ed. 58(23), 7708-7712 (2019). https://doi.org/10.1002/ anie. 201902324

196. N. Liu, M. Xu, Y. Yang, S. Zhang, J. Zhang, W. Wang, L. Zheng, S. Hong, M. Wei, $\mathrm{Au}^{\delta-}-\mathrm{O}_{\mathrm{v}}-\mathrm{Ti}^{3+}$ interfacial site: catalytic active center toward low-temperature water gas shift reaction. ACS Catal. 9(4), 2707-2717 (2019). https://doi. org/10.1021/acscatal.8b04913

197. S. Xu, S. Chansai, C. Stere, B. Inceesungvorn, A. Goguet et al., Sustaining metal-organic frameworks for water-gas shift catalysis by non-thermal plasma. Nat. Catal. 2(2), 142148 (2019). https://doi.org/10.1038/s41929-018-0206-2

198. S.C. Ammal, A. Heyden, Understanding the nature and activity of supported platinum catalysts for the water-gas shift reaction: from metallic nanoclusters to alkali-stabilized single-atom cations. ACS Catal. 9(9), 7721-7740 (2019). https ://doi.org/10.1021/acscatal.9b01560

199. M. Xu, S. Yao, D. Rao, Y. Niu, N. Liu et al., Insights into interfacial synergistic catalysis over $\mathrm{Ni} @ \mathrm{TiO}_{2-\mathrm{x}}$ catalyst toward water-gas shift reaction. J. Am. Chem. Soc. 140(36), 11241-11251 (2018). https://doi.org/10.1021/jacs.8b03117

200. D.B. Pal, R. Chand, S.N. Upadhyay, P.K. Mishra, Performance of water gas shift reaction catalysts: a review. Renew. Sustain. Energy Rev. 93, 549-565 (2018). https://doi. org/10.1016/j.rser.2018.05.003

201. J.A. Rodriguez, E.R. Remesal, P.J. Ramírez, I. Orozco, Z. Liu, J. Graciani, S.D. Senanayake, J.F. Sanz, Water-gas shift reaction on $\mathrm{K} / \mathrm{Cu}(111)$ and $\mathrm{Cu} / \mathrm{K} / \mathrm{TiO}_{2}(110)$ surfaces: alkali promotion of water dissociation and production of $\mathrm{H}_{2}$. ACS Catal. 9(12), 10751-10760 (2019). https://doi.org/10.1021/ acscatal.9b03922

202. M. Zhu, P. Tian, R. Kurtz, T. Lunkenbein, J. Xu et al., Strong metal-support interactions between copper and iron oxide during the high-temperature water-gas shift reaction. Angew. Chem. Int. Ed. 131(27), 9181-9185 (2019). https:// doi.org/10.1002/anie.201903298

203. J. Shi, A. Wittstock, C. Mahr, M.M. Murshed, T.M. Gesing, A. Rosenauer, M. Bäumer, Nanoporous gold functionalized with praseodymia-titania mixed oxides as a stable catalyst for the water-gas shift reaction. Phys. Chem. Chem. Phys. 21(6), 3278-3286 (2019). https://doi.org/10.1039/C8CP06040A

204. D. Damma, D. Jampaiah, A. Welton, P. Boolchand, A. Arvanitis, J. Dong, P.G. Smirniotis, Effect of Nb modification on the structural and catalytic property of $\mathrm{Fe} / \mathrm{Nb} / \mathrm{M}(\mathrm{M}=\mathrm{Mn}$ $\mathrm{Co}, \mathrm{Ni}$, and $\mathrm{Cu}$ ) catalyst for high temperature water-gas shift reaction. Catal. Today (2019). https://doi.org/10.1016/j.catto d.2019.02.029

205. X. Cui, H.-Y. Su, R. Chen, L. Yu, J. Dong et al., Room-temperature electrochemical water-gas shift reaction for high purity hydrogen production. Nat. Commun. 10(1), 86 (2019). https://doi.org/10.1038/s41467-018-07937-w 